\title{
Antibiotic lock therapy: review of technique and logistical challenges
}

\author{
This article was published in the following Dove Press journal: \\ Infection and Drug Resistance \\ 12 December 2014 \\ Number of times this article has been viewed
}

\author{
Julie Ann Justo \\ P Brandon Bookstaver \\ Department of Clinical Pharmacy and \\ Outcomes Sciences, South Carolina \\ College of Pharmacy, University of \\ South Carolina, Columbia, SC, USA
}

Correspondence: P Brandon Bookstaver Department of Clinical Pharmacy and Outcomes Sciences, South Carolina College of Pharmacy, University of South Carolina, 7I 5 Sumter St, Columbia, SC, USA

Tel +I 8037774786

Fax +I 8037772820

Email bookstaver@sccp.sc.edu

\begin{abstract}
Antibiotic lock therapy (ALT) for the prevention and treatment of catheter-related bloodstream infections is a simple strategy in theory, yet its real-world application may be delayed or avoided due to technical questions and/or logistical challenges. This review focuses on these latter aspects of ALT, including preparation information for a variety of antibiotic lock solutions (ie, aminoglycosides, beta-lactams, fluoroquinolones, folate antagonists, glycopeptides, glycylcyclines, lipopeptides, oxazolidinones, polymyxins, and tetracyclines) and common clinical issues surrounding ALT administration. Detailed data regarding concentrations, additives, stability/ compatibility, and dwell times are summarized. Logistical challenges such as lock preparation procedures, use of additives (eg, heparin, citrate, or ethylenediaminetetraacetic acid), timing of initiation and therapy duration, optimal dwell time and catheter accessibility, and risks of ALT are also described. Development of local protocols is recommended in order to avoid these potential barriers and encourage utilization of ALT where appropriate.
\end{abstract}

Keywords: antibiotic lock, biofilm, bacteremia, catheter-related bloodstream infection

\section{Introduction}

The prevention and management of catheter-related bloodstream infections (CRBSI) is a significant health care challenge. CRBSI occur at an estimated rate of 41,000 infections in US hospitals annually. ${ }^{1}$ This rate varies based on factors such as hospital bed size, medical school affiliation of the hospital, and type of unit/facility (eg, burn critical care unit, inpatient medical ward, rehabilitation facility). In US medical and surgical units of any acuity level, the most recent data from 2012 estimate the mean incidence rate of CRBSI at 0.8 to 0.9 per 1,000 central line days. ${ }^{2}$ However, patients in both medical and surgical critical care units are at higher overall risk of developing CRBSI compared to similar patient populations in inpatient wards due to increased central venous catheter $(\mathrm{CVC})$ utilization, averaging $0.35-0.59$ central line days per 1 patient-day compared to only $0.15-0.17$ in inpatient wards. ${ }^{2}$ Among critically ill patients, those in burn units or long-term care acute care hospitals are at particularly high risk of developing CRBSI (mean rates of 3.4 and 1.6 CRBSI per 1,000 central line days, respectively). While overall CRBSI rates appear to have decreased in the last $10-15$ years, ${ }^{3}$ they remain a substantial source of morbidity and mortality in the health care system.

Clinical practice guidelines recommend antibiotic lock therapy (ALT) for both prevention and treatment of catheter-related infections (CRI)., ${ }^{4,5}$ Guidelines from the Centers for Disease Control and Prevention recommend ALT as prophylaxis for patients with long-term catheters and a history of multiple CRI despite maximal efforts 
to follow aseptic technique. ${ }^{4}$ Guidelines from the Infectious Diseases Society of America (IDSA) for the diagnosis and management of CRI recommend antibiotic locks as adjunctive therapy specifically for catheter salvage in cases where the catheter is not removed. ${ }^{5} \mathrm{CVC}$ removal remains first-line therapy for management of CRI, especially in cases of Staphylococcus aureus and resistant gram-negative pathogens, including Pseudomonas aeruginosa. Bustos et al have previously reviewed the diagnosis and treatment of CRI in detail. ${ }^{6}$ This review focuses on the technical aspects of ALT for prevention and treatment of CRBSI in particular, including solution preparation and logistical challenges regarding administration. Details regarding non-antibiotic lock solutions, including antiseptic agents (eg, ethanol) and antifungals, are not discussed in this review.

\section{Antibiotic activity against biofilms}

Intravascular catheters and other implanted medical devices routinely develop microbial biofilms on their inert surfaces. A biofilm is defined as a microbial community with cells attached to a substratum or each other and embedded in a matrix of extracellular polymeric substances (EPS), or glycocalyx. EPS density varies within the biofilm itself, appearing densest in deeper layers immediately surrounding the colonies of microorganisms. Its density decreases in more superficial layers, leading to the formation of water channels in and around the biofilm matrix. ${ }^{7}$ Such channels allow for the transfer of nutrients, waste products, quorum-sensing molecules, and other substances (including antibiotics), similar to the function of a circulatory system in a multicellular organism.

Biofilms represent a form of adaptive resistance resulting in a significant reduction of antibiotic susceptibility by tento 1,000-fold (based on minimal inhibitory concentrations [MIC]). The exact mechanisms of antibiotic resistance within biofilms remain unclear, yet a common hypothesis is subtherapeutic exposure of biofilm cells to antibiotics. Biofilms may slow the distribution of antibiotics via charge interaction, size exclusion, viscosity of the matrix, and possible adsorption to proteins. EPS may also inactivate antibiotic molecules prior to reaching biofilm cells. Table 1 summarizes the biofilm penetration of select antibiotics. The extent of penetration varies widely (range $0 \%-100 \%$ ), being excellent with agents such as fluoroquinolones and rifamycins, variable with beta-lactams and vancomycin, and attenuated with aminoglycosides. This variability is likely due to the heterogeneity in biofilm composition, the physiochemical properties of antibiotics, and study design. Individual biofilms are a complex mixture of polysaccharides (eg, alginate), proteins, and DNA, with significant inter- and intra-species composition variability. Due to the high content of polyanionic substances, positively charged drugs (eg, aminoglycosides) may bind to EPS and exhibit a particularly attenuated distribution into biofilm. ${ }^{8}$ Differences in study methodology may also account for the wide range of observed penetration, including aspects such as the site (eg, edge or center of the biofilm) and timing (eg, 1 , $6,24,72$ hours, or continuously) of antibiotic concentration measurement. Further studies have suggested that not only the extent, but also the attenuated rate of antibiotic penetration may play a role in antibiotic resistance. ${ }^{9}$

Alterations in drug penetration are not the sole factor determining antibiotic resistance in biofilms. Biofilm cells are often inherently more resistant to antibiotics than planktonic cells. They may express additional resistance factors (increased efflux pumps, stress response regulons, inactivating enzymes) and exhibit a slower growth rate. Due to the growth-dependent mechanisms of action of most antibiotics, the killing effect is often diminished in these sessile biofilm cells. The multifactorial nature of biofilm resistance to antibiotics is well-illustrated by data suggesting biofilm penetration is unrelated to the ability of the antibiotic to disrupt biofilm or kill biofilm cells. ${ }^{10,11}$ One study showed ampicillin did not penetrate the biofilm of a wild-type strain of Klebsiella pneumoniae ( $0 \%$ penetration), but was able to rapidly penetrate the biofilm of a mutant $K$. pneumoniae strain where beta-lactamase activity was eliminated (80\%-100\% penetration). ${ }^{11}$ Even so, beta-lactamase-negative biofilm cells with adequate ampicillin exposure displayed resistance to ampicillin when compared to beta-lactamase-negative planktonic cells, suggesting poor penetration alone did not account for the observed resistance. ${ }^{11}$ Alternatively, streptomycin, an agent with poor biofilm penetration of $0 \%-60 \%$, has exhibited comparable biofilm removal and killing (14\%-17\% and $15 \%-40 \%$, respectively) as the readily penetrating agent, ciprofloxacin (100\% penetration, $12 \%-23 \%$ removal, $14 \%-36 \%$ killing). ${ }^{10}$ Thus, the ideal antibiotic for treatment of biofilm should display adequate penetration into EPS as well as a potent activity against biofilm cells. The antimicrobial effect of potential additives, such as ion chelators like ethylenediaminetetraacetic acid (EDTA) and citrate, should also be considered. Such agents have been shown to disrupt biofilm and exhibit synergistic activity with antibiotics. ${ }^{12,13}$

\section{Antibiotic lock solutions}

In general, antibiotic lock solutions combine a highly concentrated antibiotic (100-1,000 times planktonic MIC) with 
Table I Summary of biofilm penetration for select antibiotics

\begin{tabular}{|c|c|c|c|c|}
\hline Antibiotic class/agent & Microorganism & Extent of penetration & Rate of penetration & Reference \\
\hline \multicolumn{5}{|l|}{ Fluoroquinolones } \\
\hline \multirow[t]{5}{*}{ Ciprofloxacin } & Bacillus cereus, Pseudomonas fluorescens & $100 \%$ & NR & 10 \\
\hline & Pseudomonas aeruginosa & $100 \%$ & Rapid & 74 \\
\hline & P. aeruginosa & $25 \%-50 \%$ & Rapid & 75 \\
\hline & Klebsiella pneumoniae & $80 \%-100 \%$ & Rapid & 11 \\
\hline & Staphylococcus aureus, Staphylococcus epidermidis & $86 \%-100 \%$ & NR & 76 \\
\hline Levofloxacin & P. aeruginosa & $100 \%$ & Rapid & 75 \\
\hline \multicolumn{5}{|l|}{ Rifamycins } \\
\hline Rifampin & S. epidermidis & $79 \%$ to $>90 \%$ & Rapid & 77,78 \\
\hline \multicolumn{5}{|l|}{ Oxazolidinones } \\
\hline Linezolid & S. epidermidis & $\sim 100 \%$ & Rapid & 79 \\
\hline \multicolumn{5}{|l|}{ Lipopeptides } \\
\hline Daptomycin & S. epidermidis & $\geq 100 \%$ & Rapid & 80 \\
\hline \multicolumn{5}{|l|}{ Tetracyclines } \\
\hline Tetracycline & B. cereus, $P$. fluorescens & $88 \%-93 \%$ & NR & 10 \\
\hline \multicolumn{5}{|l|}{ Macrolides } \\
\hline \multirow[t]{2}{*}{ Erythromycin } & B. cereus, P. fluorescens & $72 \%-86 \%$ & NR & 10 \\
\hline & S. epidermidis & $45 \%-93 \%$ & Variable/slow & 81 \\
\hline \multicolumn{5}{|l|}{ Beta-lactams } \\
\hline \multirow[t]{4}{*}{ Ampicillin } & K. pneumoniae & $0 \%$ & NA & 11 \\
\hline & (beta-lactamase positive) & & & \\
\hline & K. pneumoniae & $80 \%-100 \%$ & Rapid & 11 \\
\hline & (beta-lactamase negative) & & & \\
\hline Oxacillin & S. aureus, S. epidermidis & $<70 \%$ & NR & 76 \\
\hline \multirow[t]{2}{*}{ Piperacillin } & P. aeruginosa & $50 \%-100 \%$ & Rapid & 75 \\
\hline & P. aeruginosa & $0 \%-15 \%$ & NR & 82 \\
\hline Cefotaxime & S. aureus, S. epidermidis & $68 \%-70 \%$ & NR & 76 \\
\hline Imipenem & P. aeruginosa & $50 \%-100 \%$ & Rapid & 75 \\
\hline \multicolumn{5}{|l|}{ Glycopeptides } \\
\hline \multirow[t]{3}{*}{ Vancomycin } & S. aureus, S. epidermidis & $<70 \%$ & NR & 76 \\
\hline & S. epidermidis & Adequate $^{c}$ & Slow & 77,83 \\
\hline & S. aureus & Adequate ${ }^{\mathrm{b}, \mathrm{d}}$ & Slow & 9 \\
\hline \multicolumn{5}{|l|}{ Aminoglycosides } \\
\hline Streptomycin & B. cereus, P. fluorescens & $0 \%-60 \%$ & NR & 10 \\
\hline Tobramycin & P. aeruginosa & $40 \%$ & Slow & 74 \\
\hline Gentamicin & P. aeruginosa & $<25 \%$ & Slow & 75 \\
\hline \multirow[t]{2}{*}{ Amikacin } & P. aeruginosa & $<25 \%$ & Slow & 75 \\
\hline & S. aureus, S. epidermidis & $79 \%-98 \%$ & NR & 76 \\
\hline
\end{tabular}

Notes: ${ }^{a}$ Comparable penetration compared to isolates of planktonic cells; ${ }^{b}$ measured as intensity of fluorescence using confocal microscopy or other methods; ${ }^{\mathrm{v}}$ vancomycin concentrations reportedly exceeded the minimal inhibitory concentrations and minimal bactericidal concentrations for tested isolates; ${ }^{\mathrm{d}}$ represents vancomycin concentrations from I5-45 $\mu \mathrm{g} / \mathrm{mL}$.

Abbreviations: NA, not applicable; NR, not reported.

an anticoagulant to allow for local instillation into the catheter lumen. The solution is allowed to dwell or is "locked" while the CVC is not in use to prevent colonization or sterilize a previously infected catheter. ALT is often utilized in clinical practice in a prophylactic modality to prevent luminal colonization and subsequent CRBSI. This practice has demonstrated significant benefit in hemodialysis-dependent patients and those with indwelling CVC for intravenous (IV) chemotherapy and total parenteral nutrition (TPN), ${ }^{5,14,15}$ ALT is also an option in the management of CRBSI as an adjunct to systemic antibiotics, increasing rates of catheter salvage. ${ }^{5,16}$ Although there is wide variability in clinical utilization of ALT among infectious diseases specialists, nearly $40 \%$ report attempting catheter salvage with ALT. ${ }^{17}$

\section{Ideal lock solution}

The ideal lock solution should possess a number of characteristics. Many, but perhaps not all, of these factors are applicable for both treatment and prophylactic modalities.

1. Spectrum of activity should include common or targeted pathogens. Although the majority of CRBSI are secondary to gram-positive organisms, protracted use of 
CVCs in high-risk patients increases the likelihood of gram-negative and fungal pathogens.

2. Ability to penetrate or disrupt a biofilm. Especially important in treatment, the ability to penetrate a biofilm and demonstrate activity against biofilm cells at concentrations 100-1,000 times standard concentrations is essential. Several lock solution additives, including ion chelators such as citrate and EDTA, can also disrupt intact biofilms.

3. Compatibility with anticoagulants. Not all CVC will require the addition of an anticoagulant (eg, heparin) to maintain patency; however, to decrease the risk of occlusion, the ability to include a low-dose heparin (eg, $<1,000$ units $/ \mathrm{mL}$ ) or an alternative ion chelator such as citrate will enhance the ability to broadly utilize a lock solution.

4. Prolonged stability. The ability to prepare lock solutions in bulk and apply extended expiration will enhance the continuation of ALT at points of transitions of care. This will be important for a pharmacy to maximize cost-effective use of lock therapy. Storage at room temperature as opposed to refrigeration is an additional advantage.

5. Low risk of toxicity and adverse events. The small volumes used in the intraluminal space do not lend themselves to high risk of toxicity. However, higher concentrations of specific agents (eg, aminoglycosides and citrate) have been associated with significant toxicity and should be avoided when using ALT. ${ }^{18,19}$ There is additional concern if these solutions are flushed as opposed to aspirated, which could expose the patient to higher concentrations of anticoagulants (eg, heparin). Ethanol at higher concentrations may be associated with minor adverse events, especially in low-weight neonates. ${ }^{14}$ Catheter occlusion is another possible adverse event with ALT, especially in the absence of a low-dose anticoagulant in solution.

6. Low potential for resistance. Although there is likely minimal systemic exposure of the antibiotic lock solution if aspirated with each exchange, use of agents with a low risk for development of resistance is important. In a treatment modality, if the systemic antibiotic is also used concurrently as a component of the lock solution, concern for resistance is diminished.

7. Cost-effectiveness. Use of certain agents (eg, linezolid, daptomycin) may be cost-prohibitive, especially when used on a larger population in a prophylactic modality. Careful consideration on maximizing compounding efficiency and stability should be done prior to initiating lock therapy with such high-cost agents.

\section{Antibiotics in solution: stability and compatibility}

Despite the variability in quality and quantity of data, many antibiotics have been investigated in lock solutions in both in vitro models and in clinical studies. Table 2 provides a detailed, referenced summary of the available data on antibiotic lock solutions. In vitro or animal data were included only when antibiotics were combined with an additive. In vivo data were included if a unique concentration of the lock solution was used. Comments on dwell time and duration of use are included when available for in vivo studies. Of note, many stability studies are conducted under varying conditions, including temperature (eg, $4^{\circ} \mathrm{C}$ vs $37^{\circ} \mathrm{C}$ ), exposure duration, and storage conditions (eg, glass vs polyurethane catheter) and should be interpreted accordingly.

Beta-lactams have been studied extensively in lock solutions. Ampicillin and cefazolin have proven stability and compatibility in combination with heparin at varying concentrations and may offer options for management of susceptible gram-positive pathogens. Cefazolin and tissue plasminogen activator (TPA) have been combined in a lock solution. ${ }^{20}$ Cefotaxime and ceftazidime have each been studied in combination with heparin, including several clinical studies with ceftazidime-based lock therapy. ${ }^{21,22}$ Absorption into plastic polymers has been described; yet despite this apparent loss of antibiotic, ceftazidime concentrations expected to be active against biofilm-producing organisms were achieved 21 days postinstillation. ${ }^{22,23}$ Beta-lactams with extended spectrums including piperacillin, piperacillin/tazobactam, and ticarcillin/ clavulanate have also been studied in combination with heparin. ${ }^{23-27}$ Cefepime has only been investigated in a single in vitro model without additives. ${ }^{28}$ There is a general lack of data regarding carbapenems in lock solutions. A single clinical study of imipenem/cilastatin in combination with heparin and an unpublished abstract suggesting meropenem and heparin stability and compatibility in a lock solution are available. ${ }^{29,30}$ More data are needed with carbapenem-based solutions as CRBSI secondary to multi-drug resistant organisms (MDRO) with limited treatment options are certain to increase over time.

Aminoglycosides, specifically amikacin, gentamicin, and tobramycin, have been studied extensively with a number of additives, including heparin, citrate, TPA, and other antimicrobials. Aminoglycosides have proven effectiveness in multiple in vitro models and are among the most commonly 

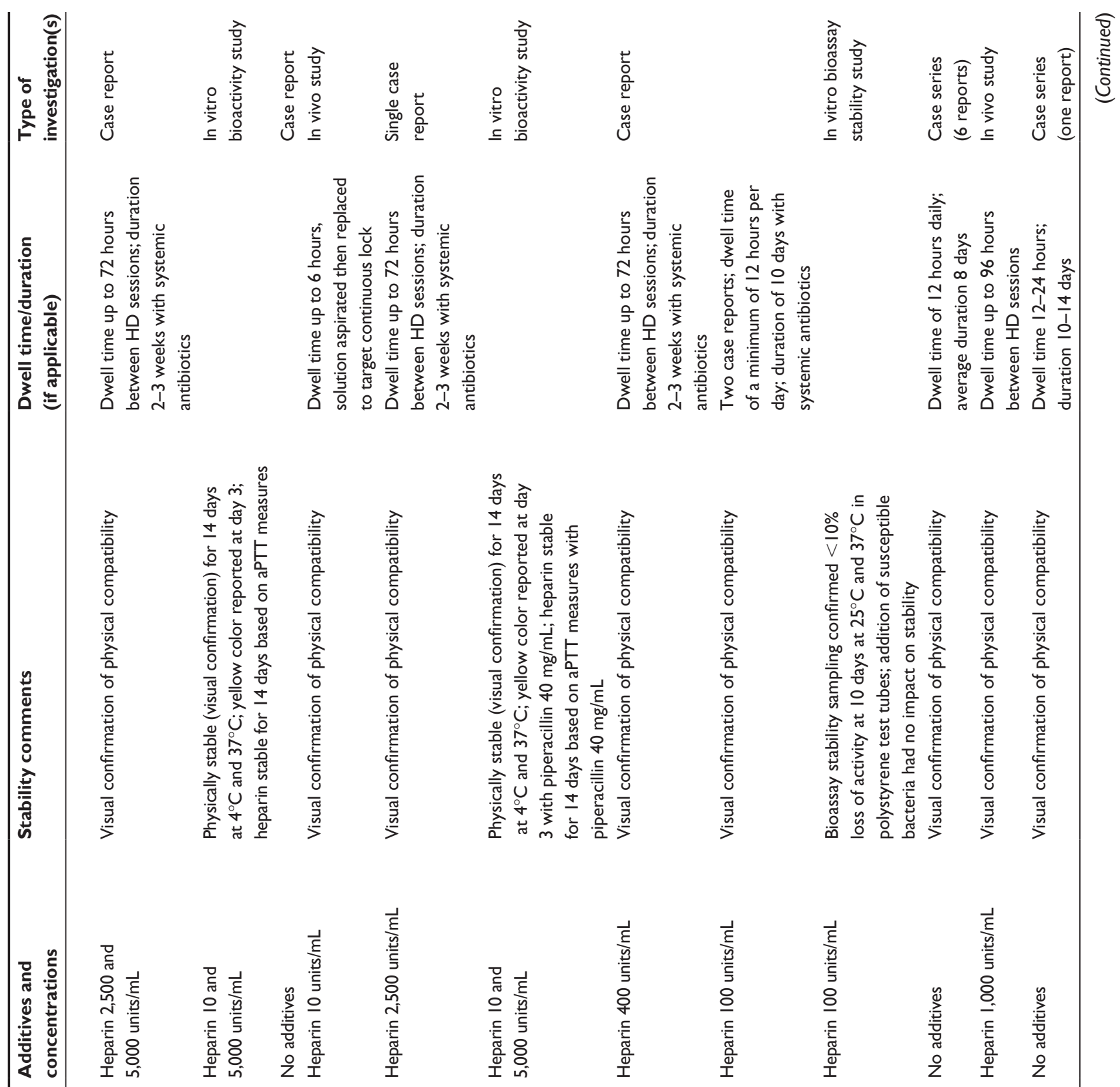

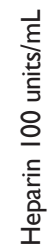

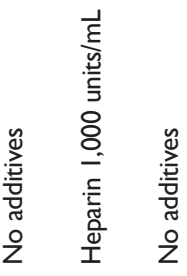

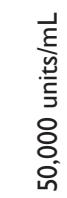

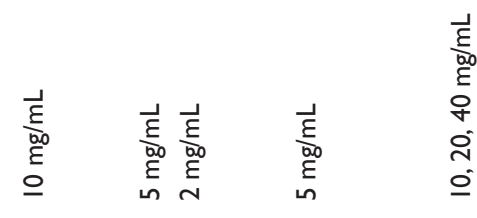

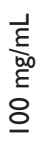
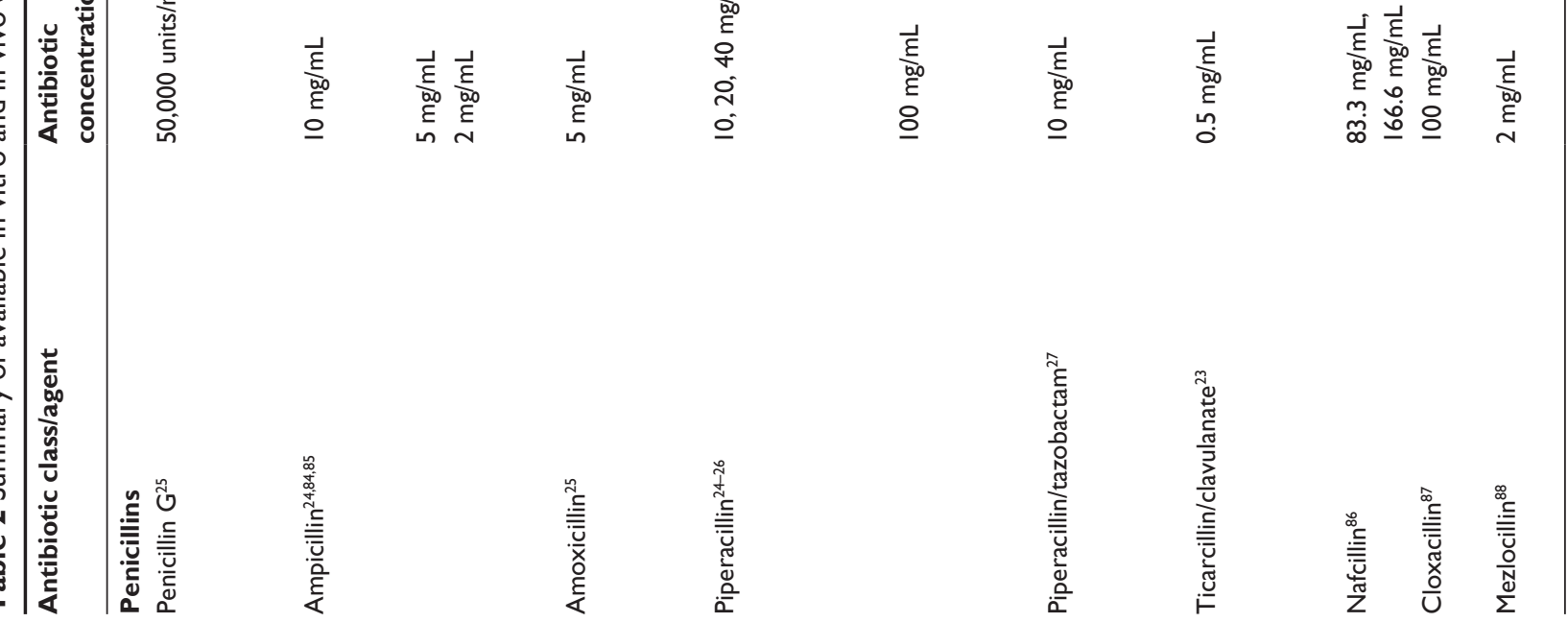


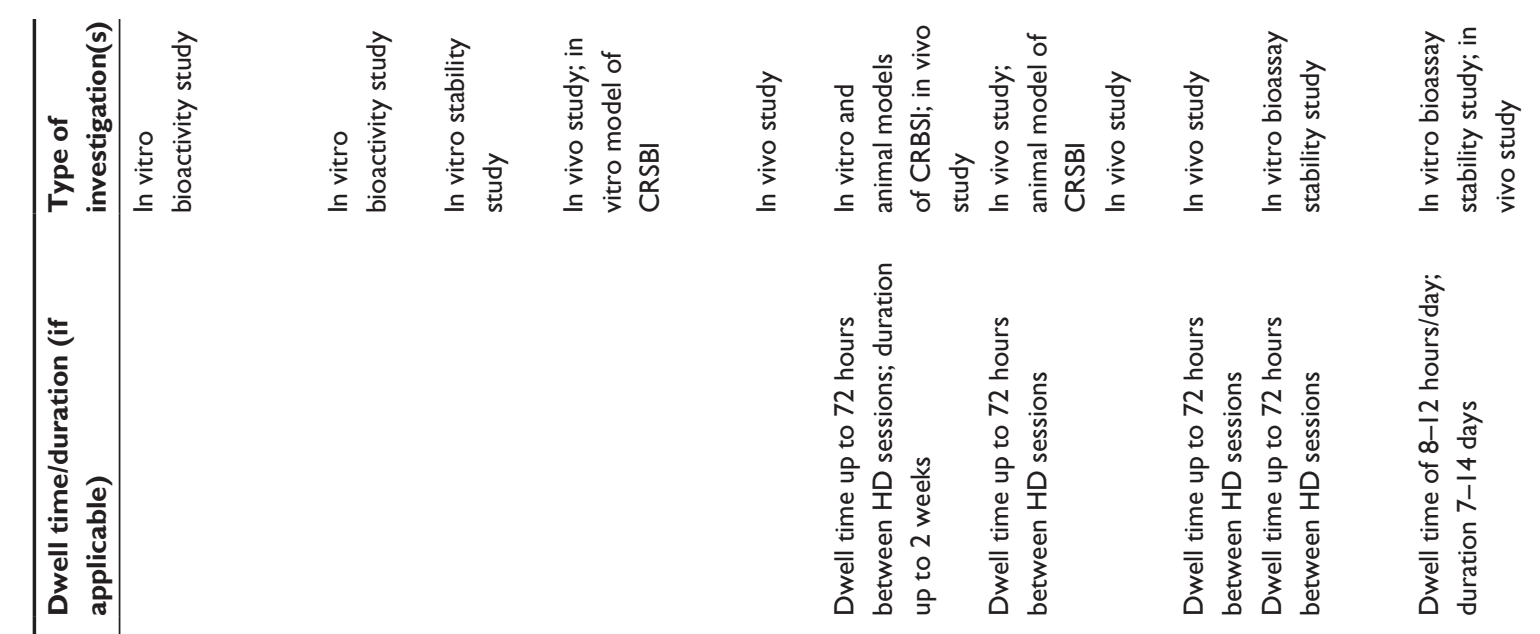

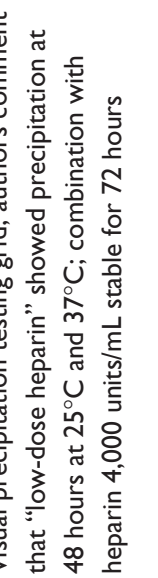

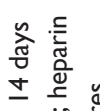
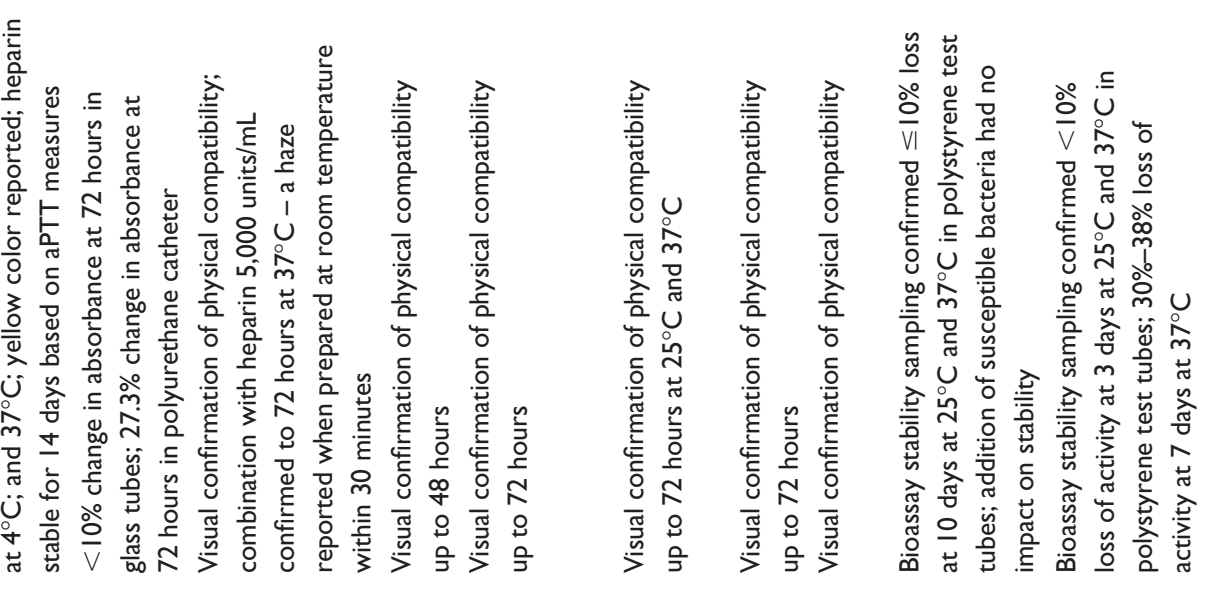

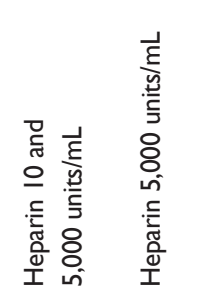

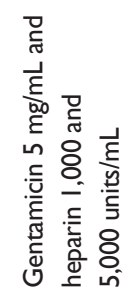

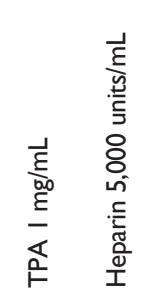

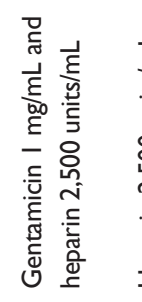

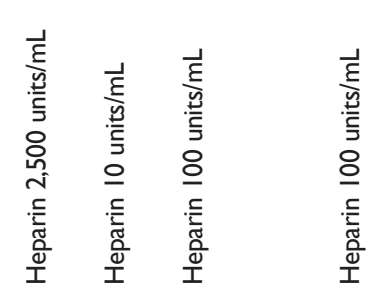

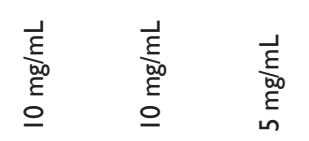

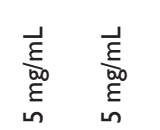

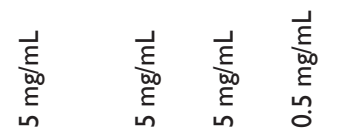

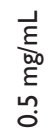
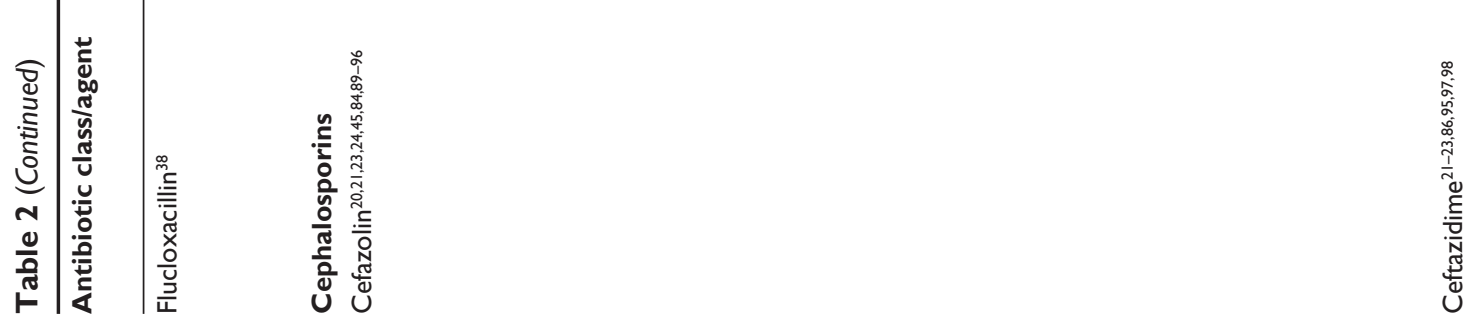


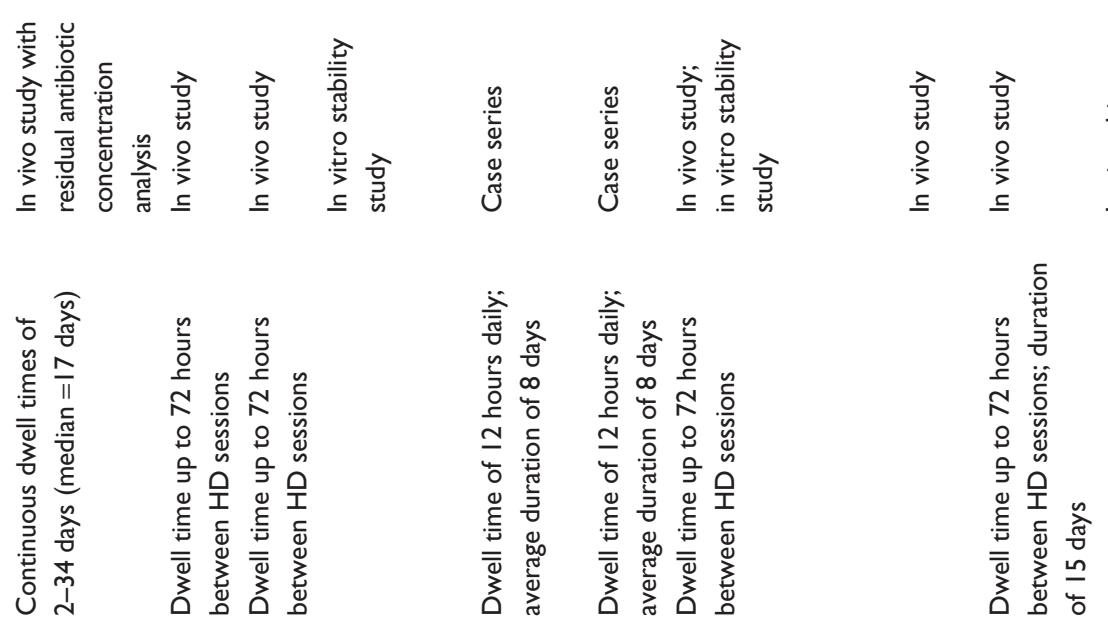
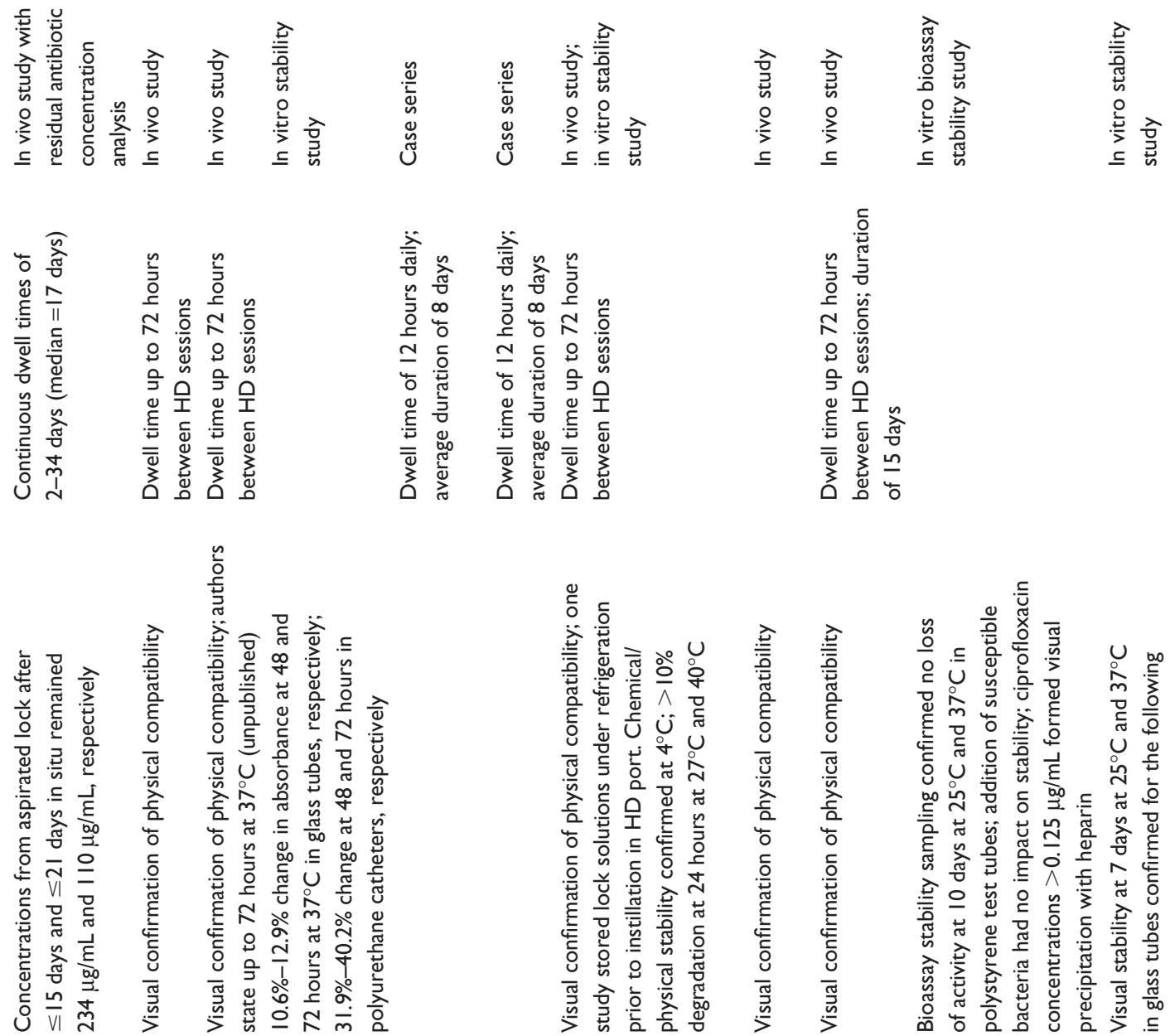

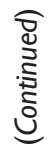
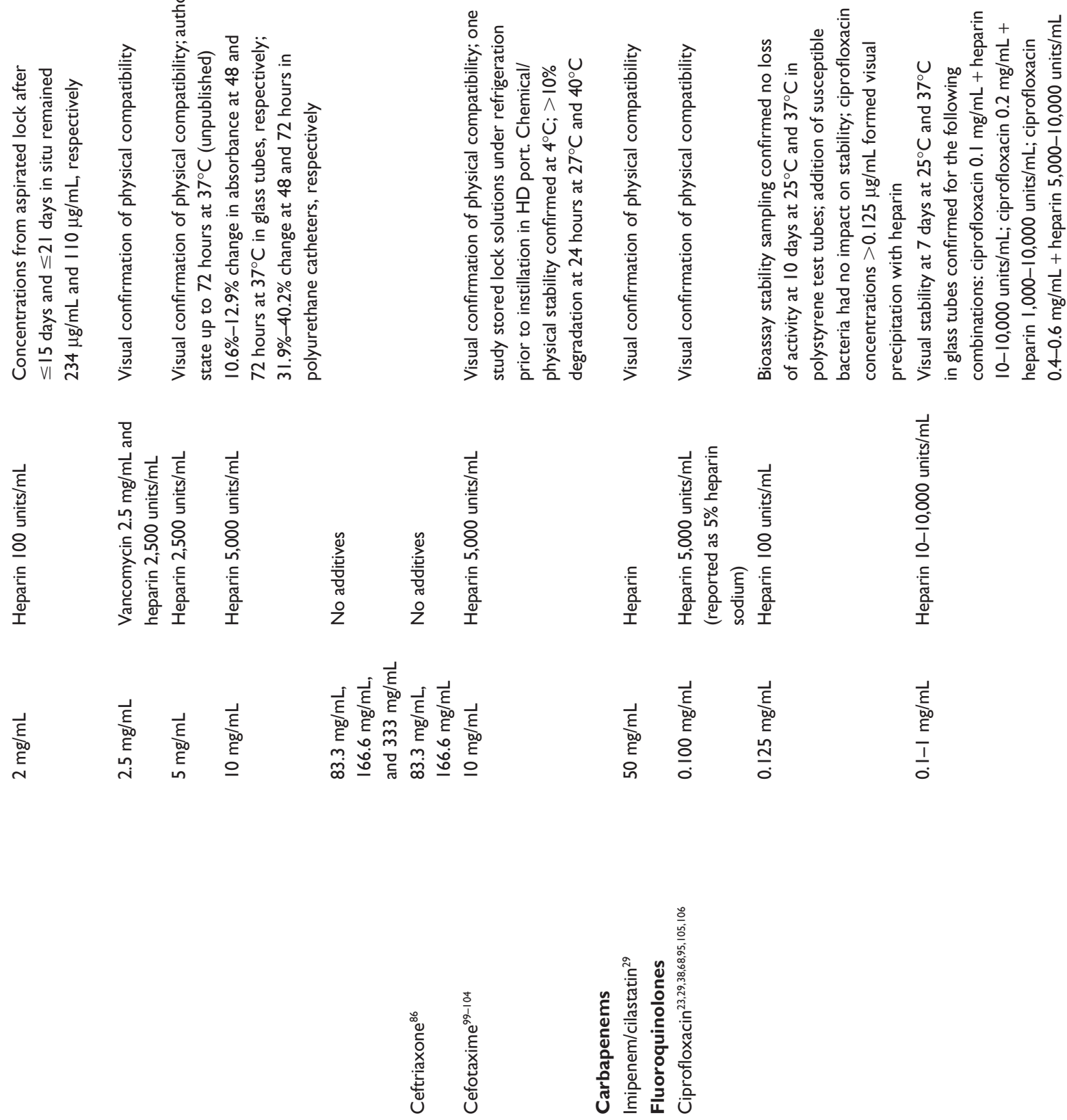


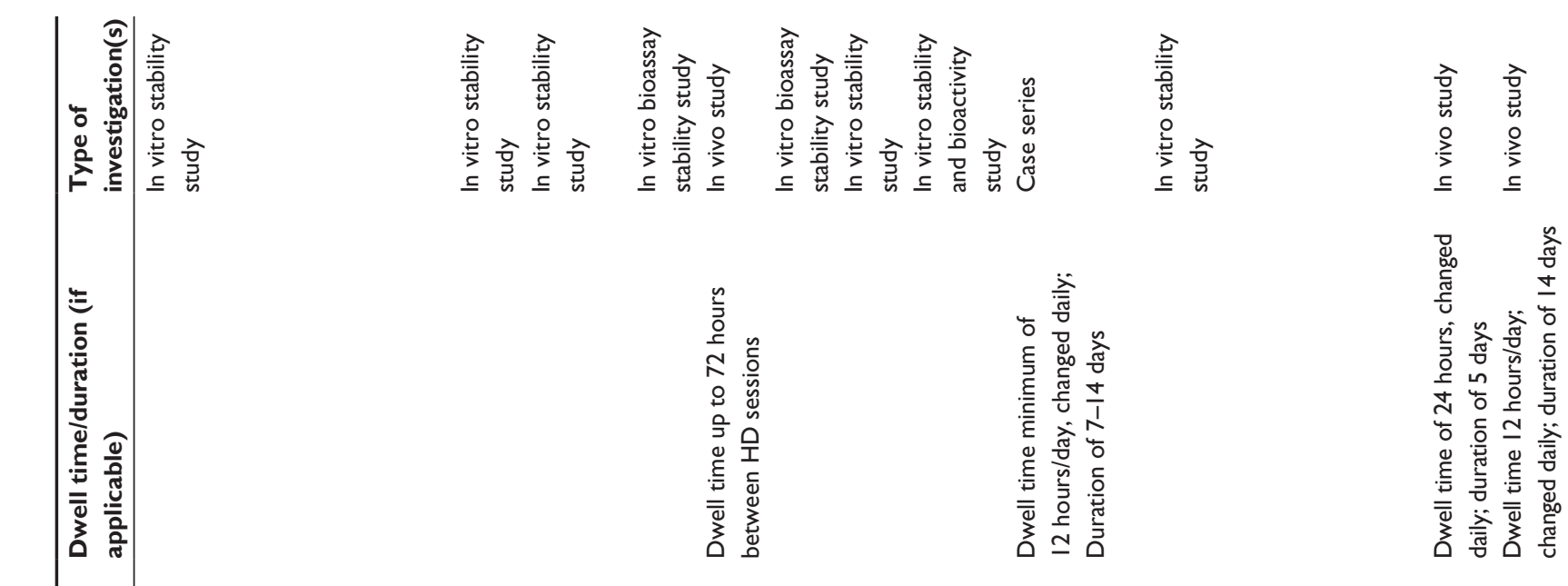

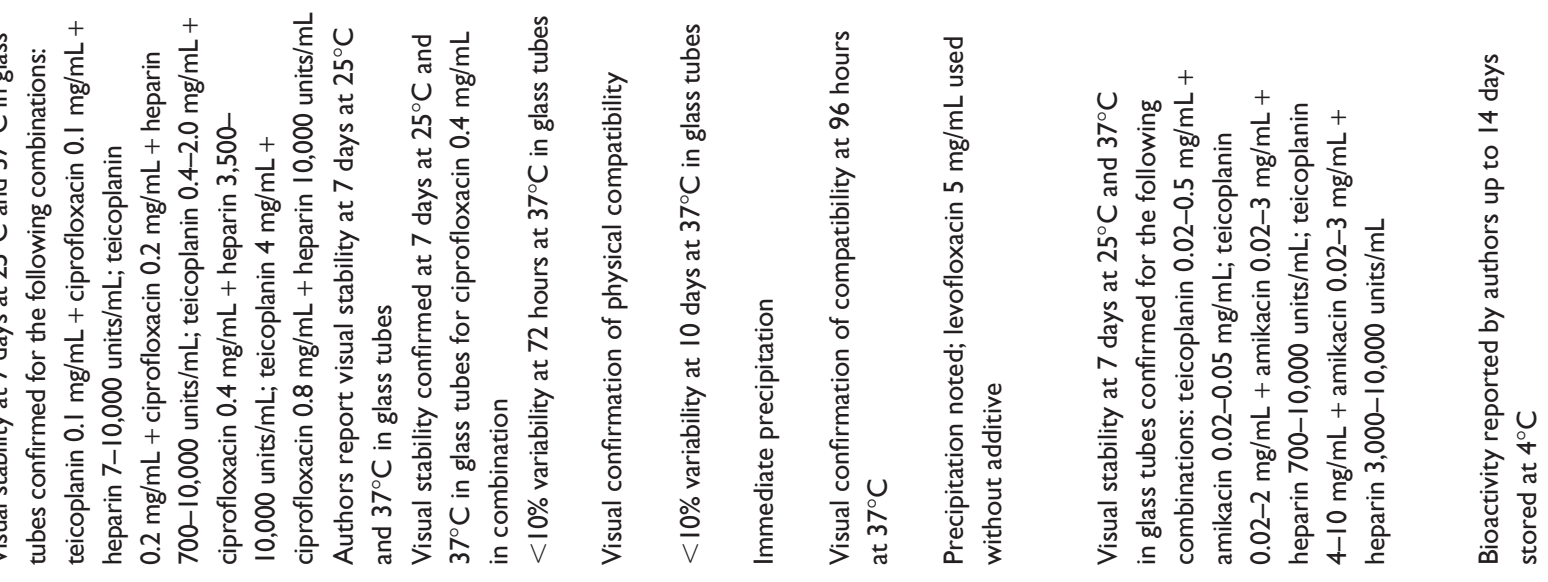

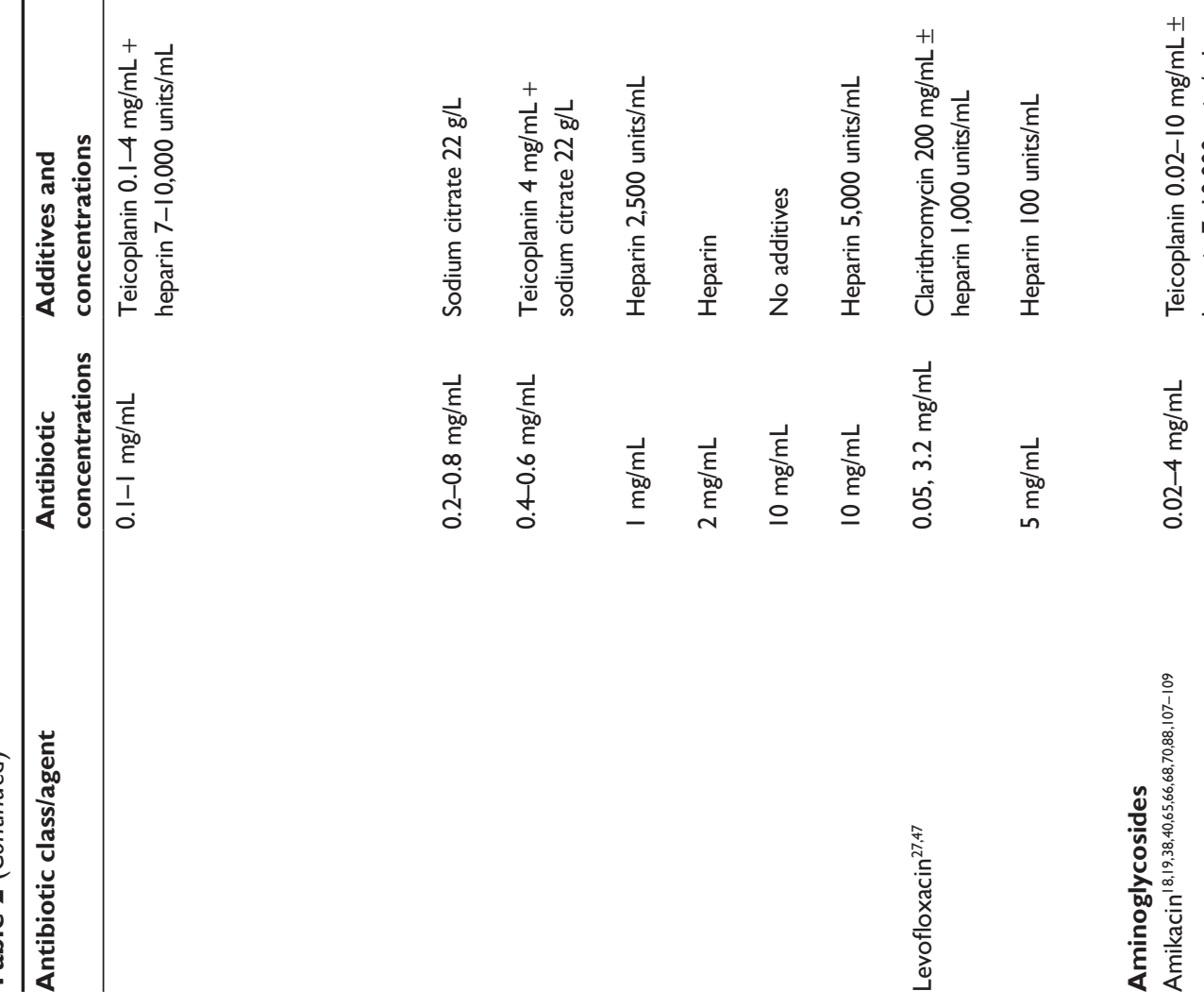




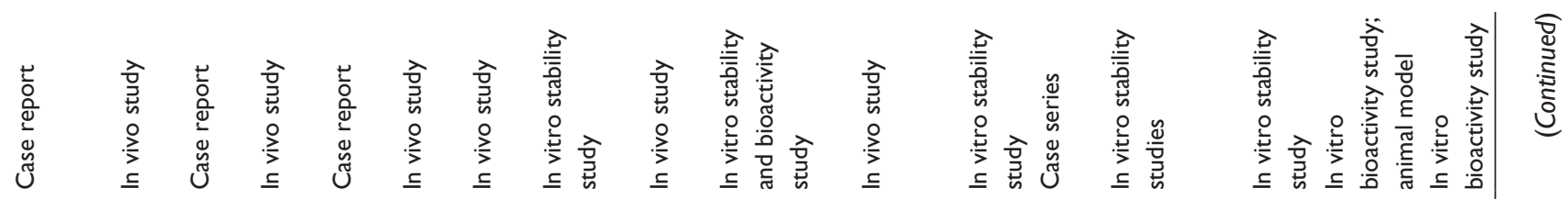
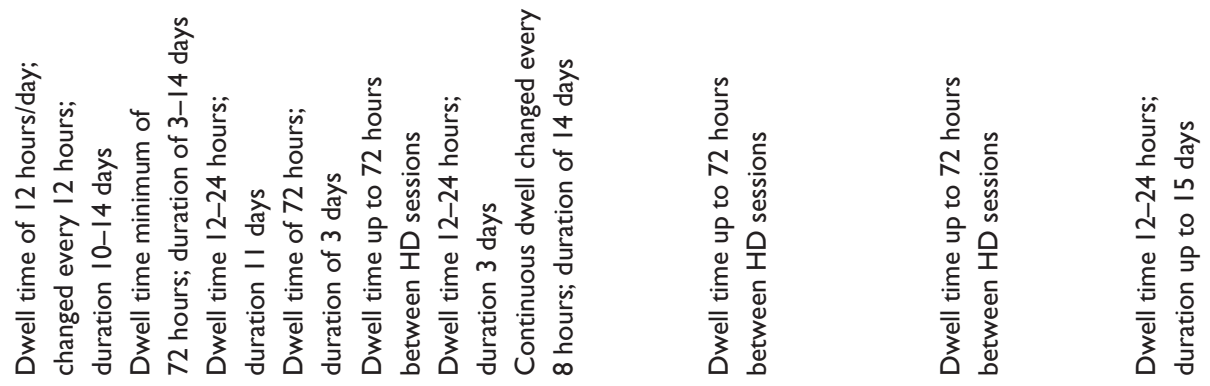

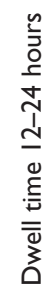
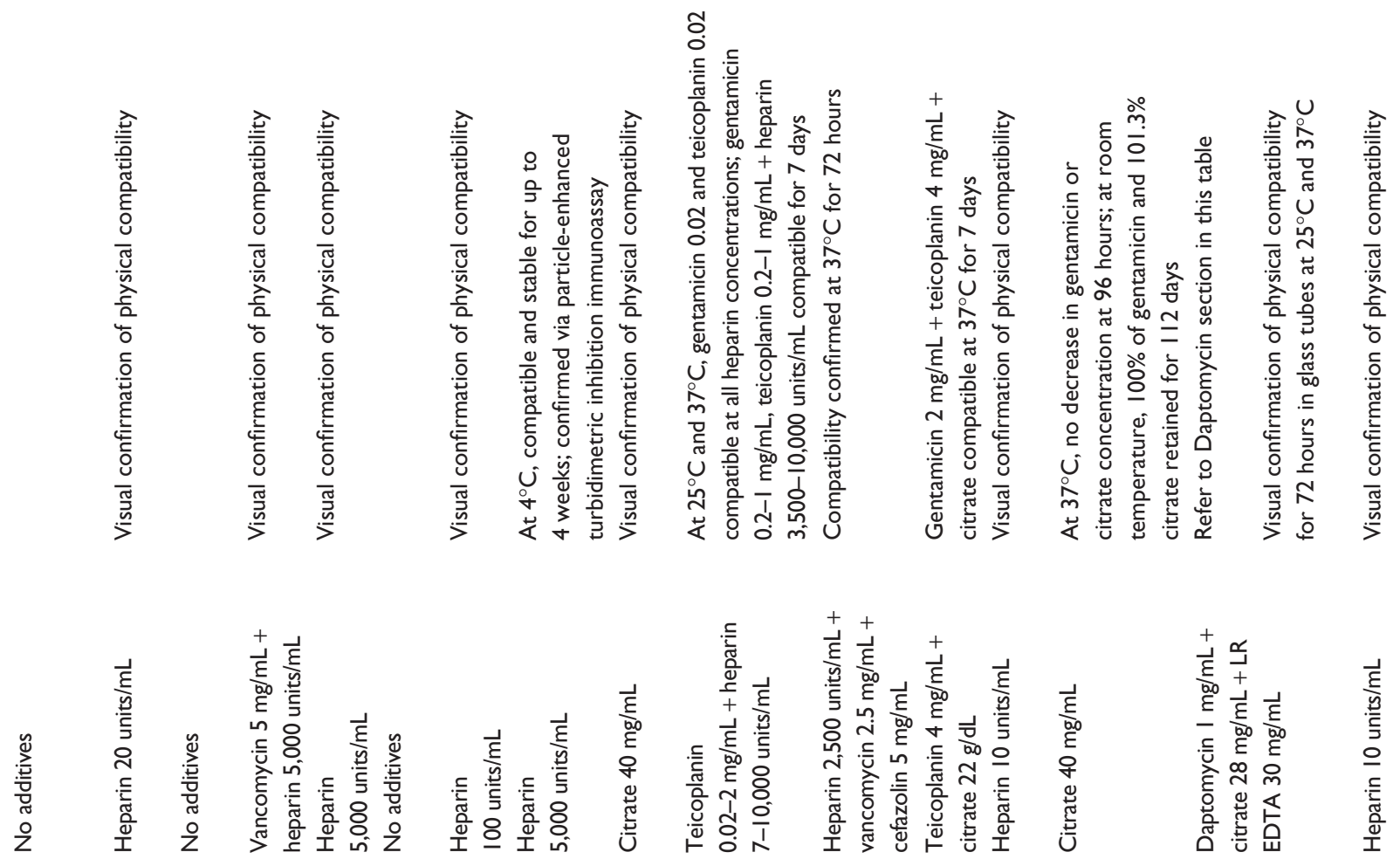

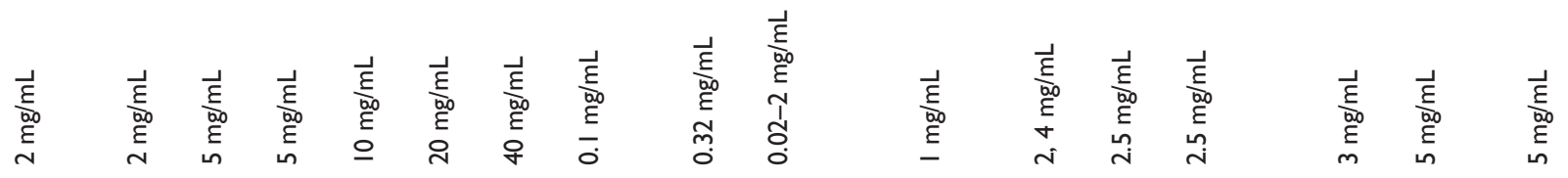

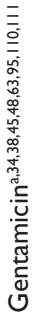



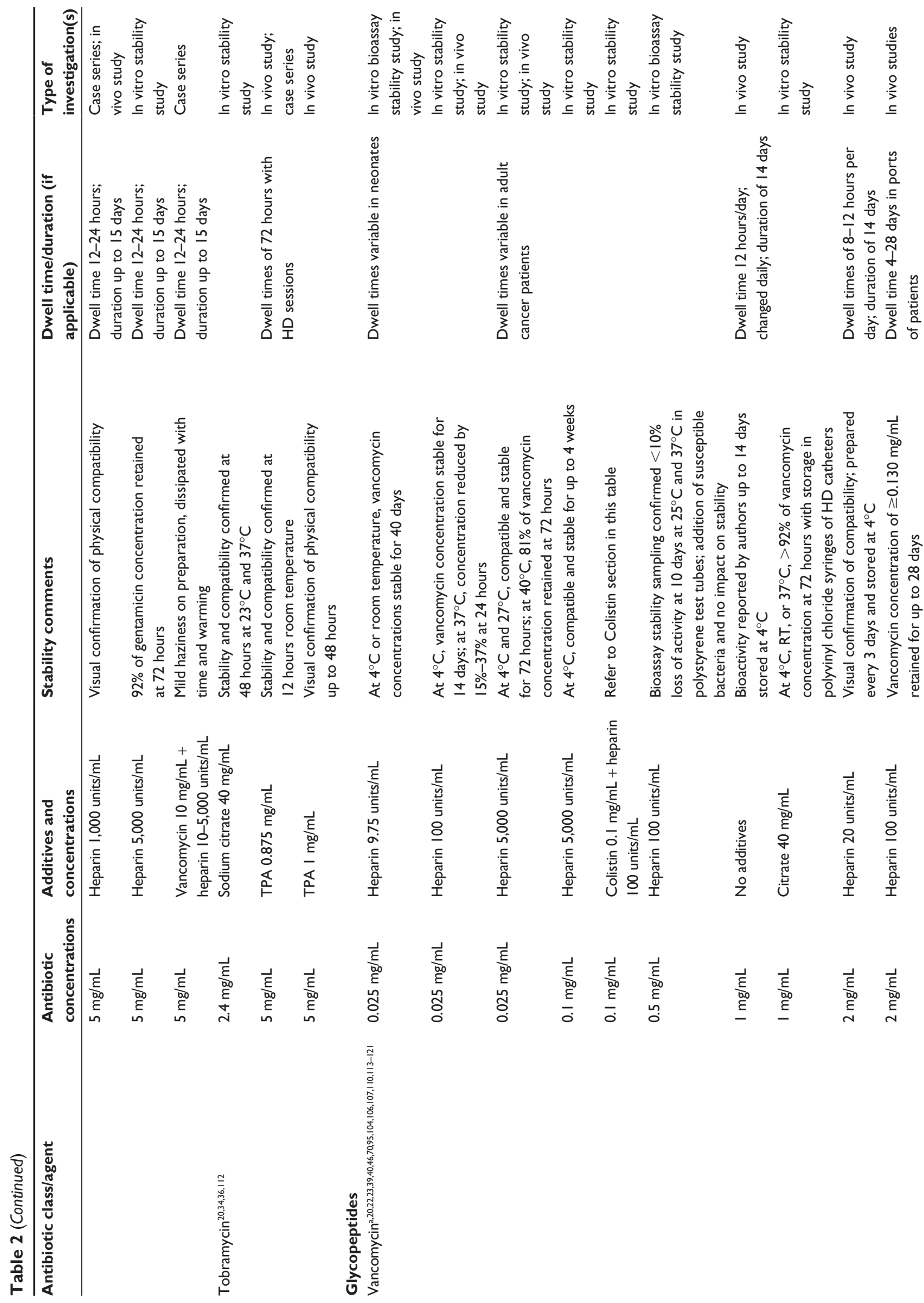


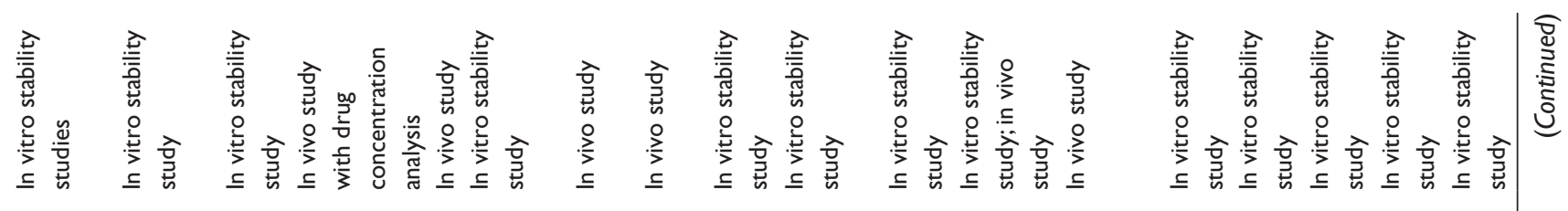
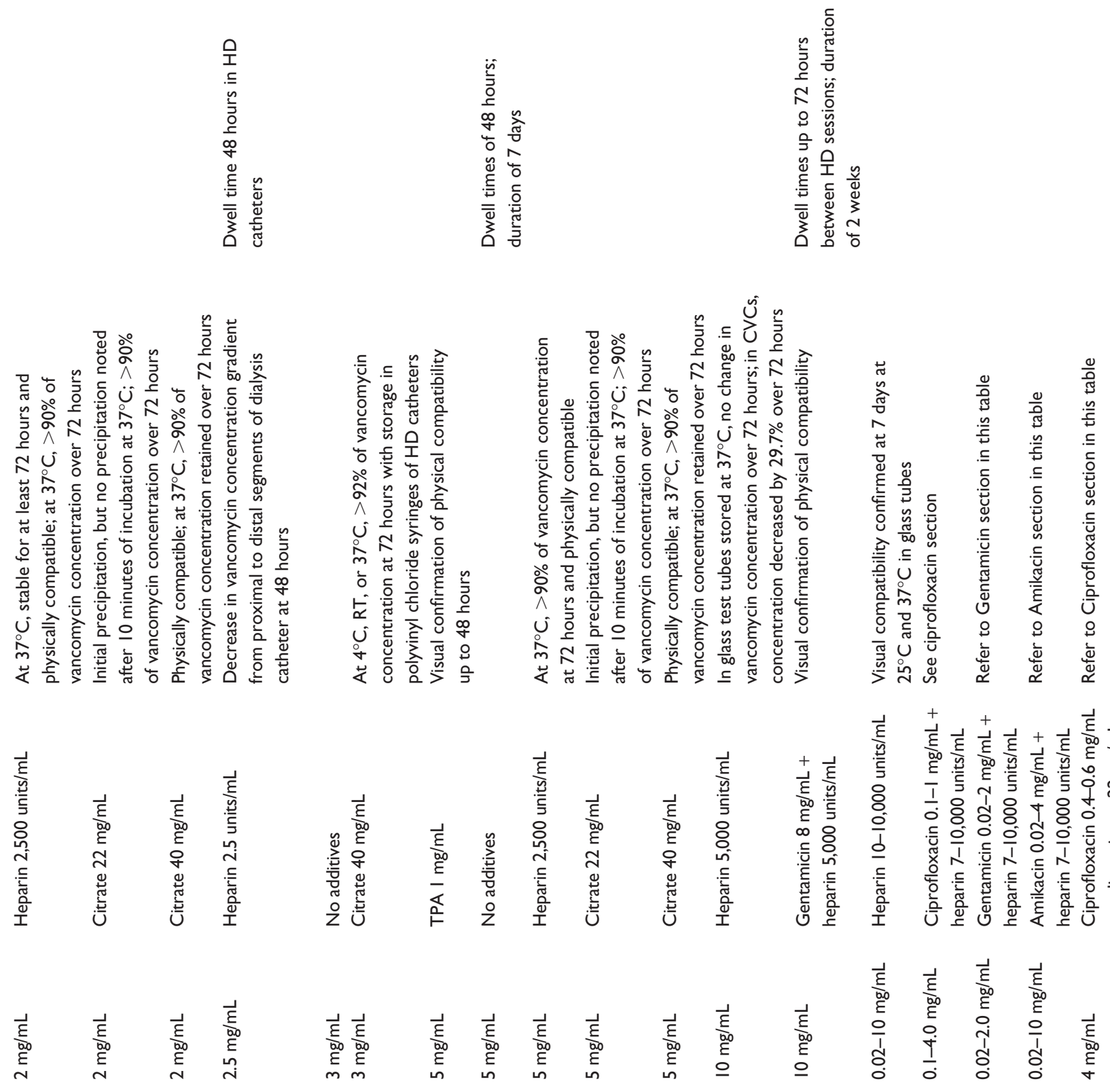


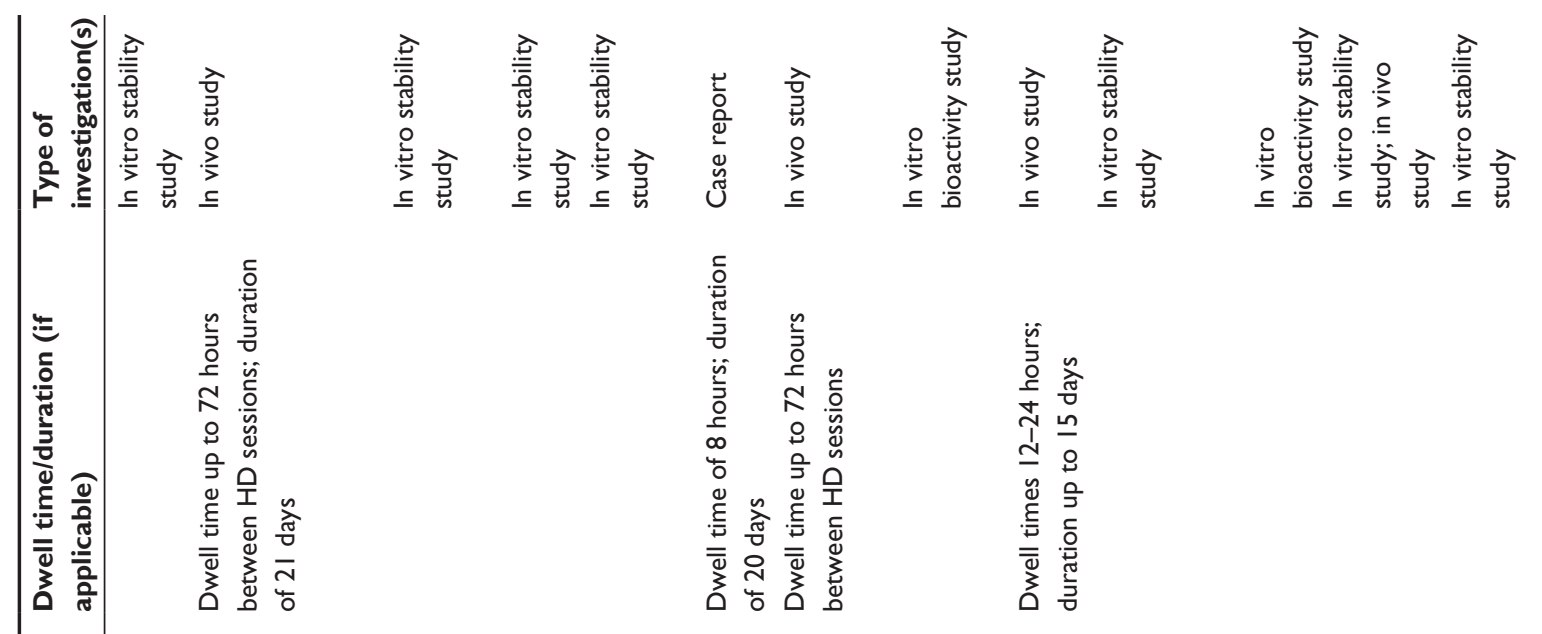




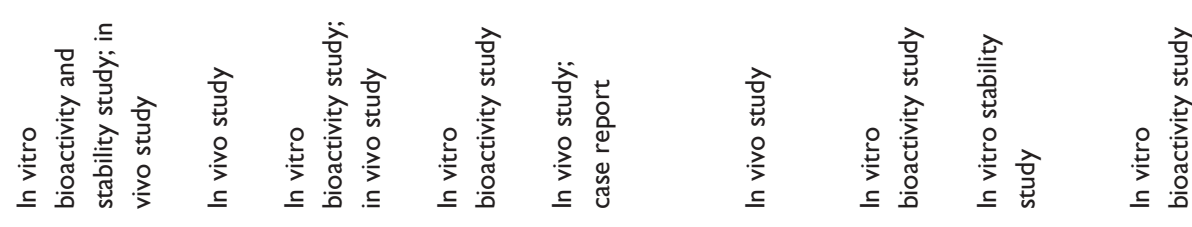
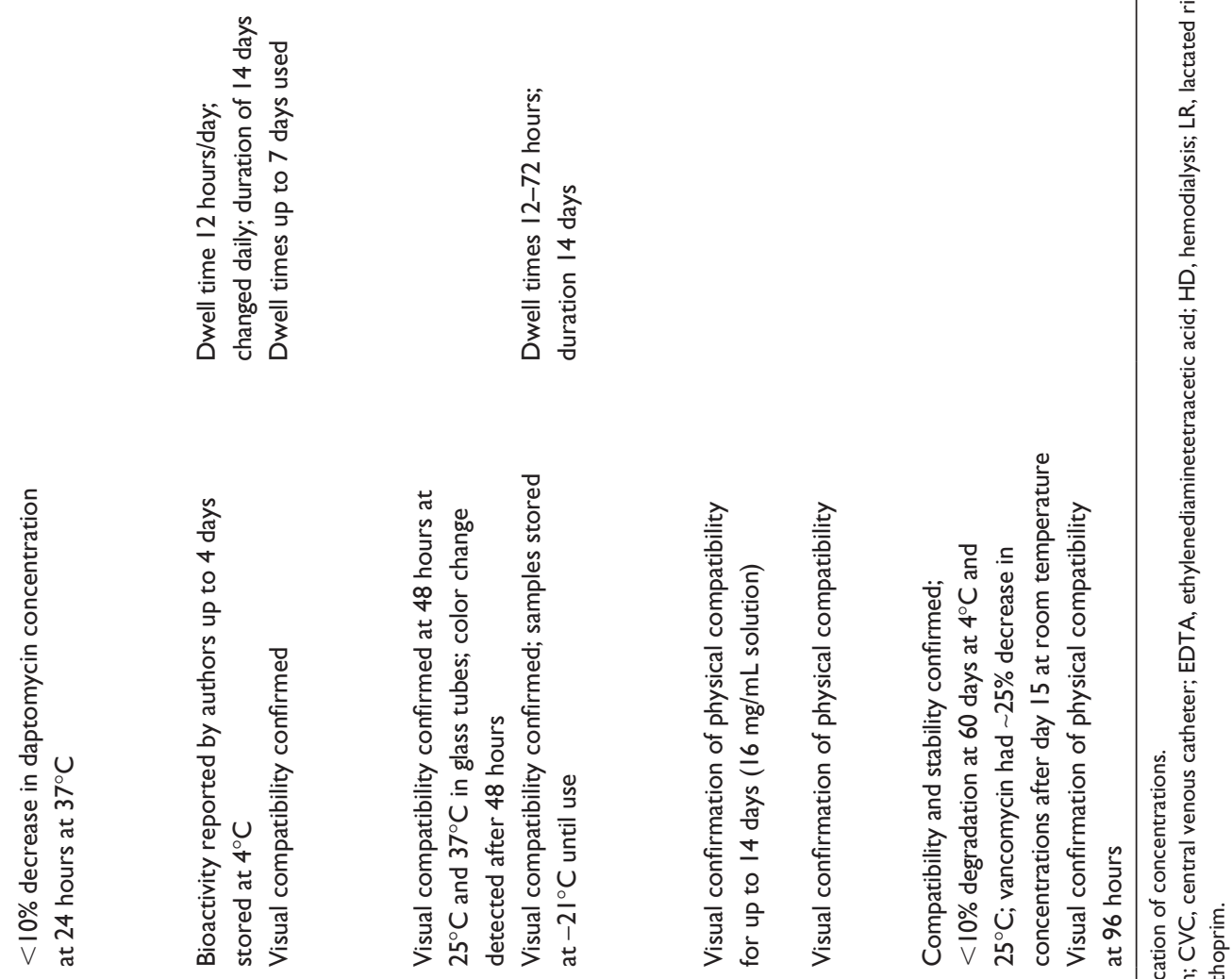

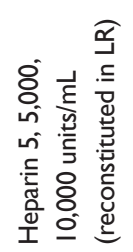

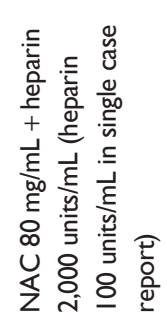

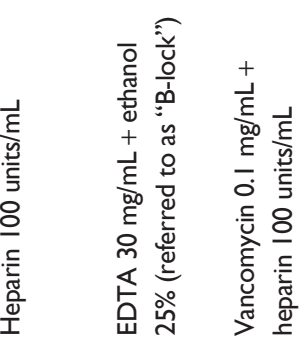

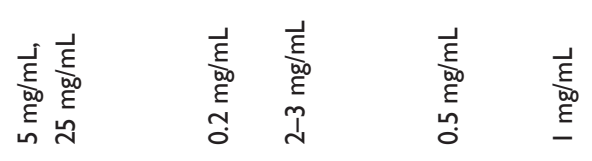
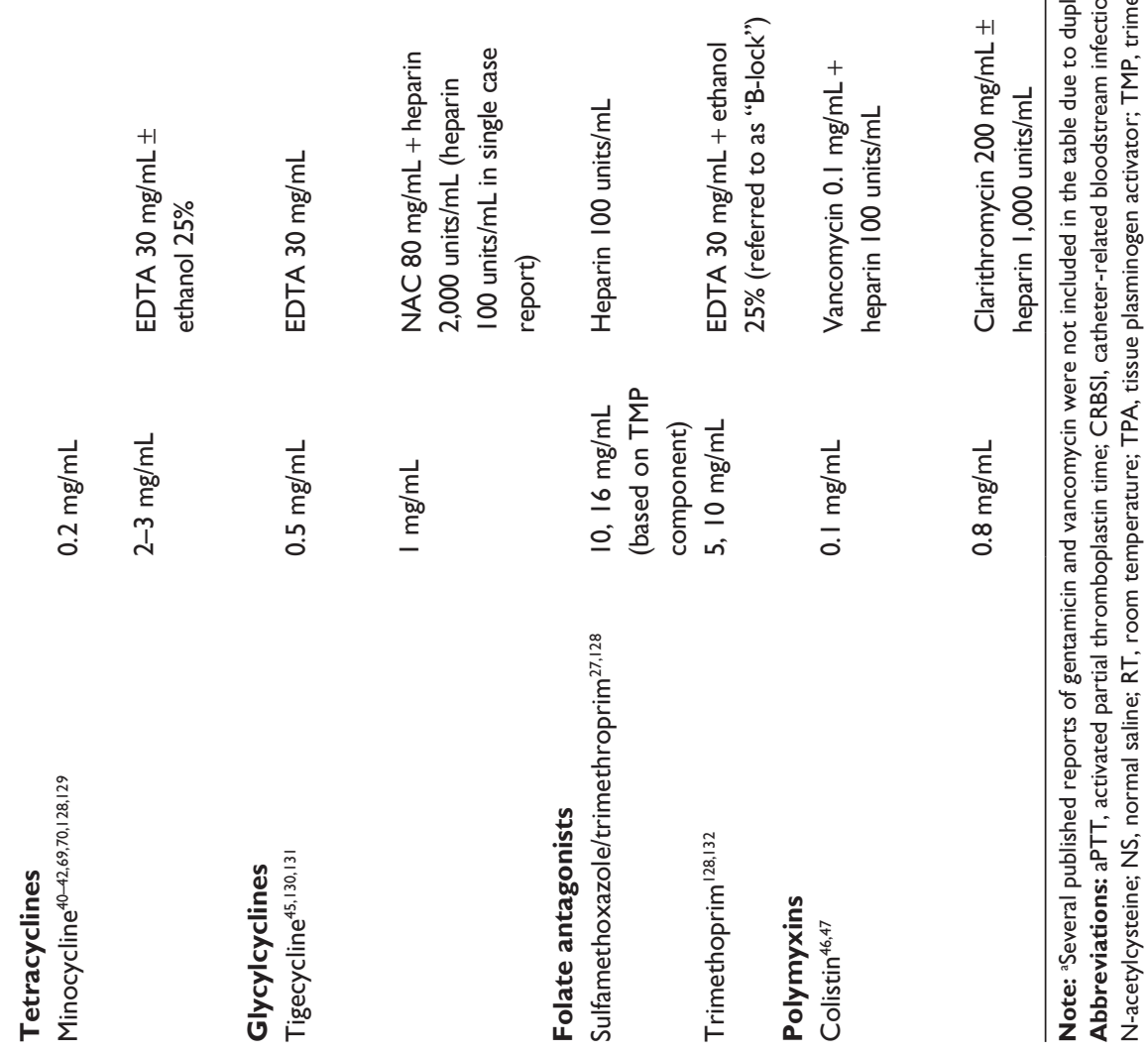
utilized solutions in CRBSI prophylaxis. Amikacin in combination with heparin alone and with vancomycin in solution has demonstrated stability. Higher concentrations of amikacin $(>10 \mathrm{mg} / \mathrm{mL})$ have been associated with ototoxicity. ${ }^{18}$ These concentrations pose a significant risk to the patient, especially when flushed into systemic circulation, and should not be utilized in a lock solution. Gentamicin is among the most studied antibiotics in lock solution. Despite the large number of in vitro and in vivo studies, concern remains about its relative compatibility and stability with heparin in solution. Conflicting results in the literature suggest the development of cloudiness or precipitation on preparation of gentamicin plus heparin lock solutions. ${ }^{31}$ Although this may be a concentration-dependent phenomenon, other factors including the relative volumes of solution components, order of preparation, temperature, and product manufacturers may contribute. Although not extensively evaluated, exposure to higher temperatures (eg, a catheter lumen) and elapsing time have been suggested to improve the solution appearance. ${ }^{31}$ Data are mostly consistent in reporting compatibility of gentamicin concentrations $<4 \mathrm{mg} / \mathrm{mL}$ combined with heparin concentrations $>1,000$ units $/ \mathrm{mL} .{ }^{32}$ Alternatively, extended stability $>100$ days has been demonstrated for gentamicin plus citrate in solution. Citrate-based solutions have shown improved clinical outcomes when compared to heparinbased controls. ${ }^{33}$ The combination of gentamicin plus citrate should be considered a viable option in both a prophylactic and treatment modality. Tobramycin has also been studied in combination with heparin, citrate, or TPA. ${ }^{20,34-36}$

Vancomycin in combination with heparin has been evaluated in a number of in vitro and clinical studies. Compatibility with heparin has been consistently demonstrated at vancomycin concentrations $<10 \mathrm{mg} / \mathrm{mL}$. Others have reported a visual haze with higher concentrations of vancomycin $(>5 \mathrm{mg} / \mathrm{mL})$ in combination with high concentrations of heparin (eg, 5,000 units/mL); however, these appear to be alleviated with slight agitation. ${ }^{31}$ Vancomycin has also been shown to be compatible in combination with citrate or TPA in solution. The combination of vancomycin plus citrate offers a nonheparinized solution that may be beneficial in many patient populations. Vancomycin has also been combined in solution with other antibiotics including gentamicin with success. As previously described, vancomycin activity against established biofilms is concentration-dependent and has shown to be inferior to comparator agents, including linezolid. ${ }^{37}$ Although not clearly demonstrated, widespread use of vancomycin in a prophylactic modality may increase the likelihood of developing resistance, and use in this manner should be cautioned.
Teicoplanin as an alternative to vancomycin has demonstrated similar compatibility with heparin up to 10,000 units $/ \mathrm{mL}$. Varying compatibility has been reported for teicoplanin in combination with citrate and other antimicrobials, including gentamicin and ciprofloxacin. ${ }^{38}$ Telavancin has shown compatibility with heparin and citrate, however there are no published reports of clinical use. ${ }^{39}$

Fluoroquinolones, specifically ciprofloxacin and levofloxacin, have been studied in a lock solution. Ciprofloxacin at low concentrations in combination with heparin at low concentrations ( $\leq 2,500$ units) has demonstrated stability and compatibility. Incompatibilities have been reported with higher concentrations of each component in solution. One study confirmed visual stability of ciprofloxacin and citrate for up to 7 days. Levofloxacin precipitation with heparin has been noted, and published use of levofloxacin in a lock solution is limited. Ciprofloxacin may offer an option for management of gram-negative CRBSI.

Tetracyclines, most commonly minocycline, have been utilized in ALT for nearly 30 years. ${ }^{40}$ The antibiofilm activity and proposed synergy with ion chelators offer a promising option as a lock solution. Minocycline in combination with the ion chelator, EDTA, has demonstrated visual compatibility in a number of in vitro models and clinical studies. Minocycline plus EDTA has demonstrated effectiveness in preventing CRBSI in pediatric cancer patients and hemodialysis-dependent adults with dwell times up to 7 days. ${ }^{41-44}$ Doxycycline plus EDTA may be a promising alternative to minocycline. Tetracyclines are not compatible with heparin. The lack of consistent availability of EDTA may limit the use of minocycline-based regimens. Future study with other ion chelators (eg, citrate) is recommended.

Several agents that may be used for resistant grampositive infections including daptomycin, linezolid, and tigecycline have been studied. Daptomycin has proven stability with heparin and citrate at varying concentrations. Reconstitution of daptomycin with Lactated Ringer's solution (LR) or supplementation of the lock solution with calcium is required for activity. ${ }^{45}$ Use with ion chelators, such as citrate, in solution cannot be recommended at this time without confirmation of bioactivity. Linezolid stability with heparin or citrate has been confirmed, although published clinical use is quite limited. Because of the limitations of linezolid therapy in CRBSI, its use as a lock solution should be reserved for very specific cases with limited treatment options. Tigecycline has been studied in combination with $\mathrm{N}$-acetylcysteine (NAC) and heparin in a lock solution with positive clinical outcomes. Concerns with tigecycline use for 
bloodstream infections should limit its use to specific patient cases as a lock solution.

Many other agents have been studied in a limited manner as lock solutions, including colistimethate, clindamycin, macrolides, sulfamethoxazole/trimethoprim (SMX/TMP), and rifamycins. Data for colistimethate and SMX/TMP are included in Table 2. Stability data for colistimethate and SMX/TMP are limited, but these may be potential options for treatment of CRBSI secondary to MDRO ${ }^{46}$ Clindamycin use in a lock solution is limited to a single published study. ${ }^{26}$ Macrolides have been utilized in lock solutions in combination due to their potential impact on biofilms. ${ }^{47,48}$ Rifamycins have been studied as in vitro models, primarily in combination with agents such as minocycline and ethanol. Because their use as a primary agent in a lock solution would not be encouraged, they are not discussed in this review. ${ }^{31}$ Dalbavancin, oritavancin, tedizolid, and ceftaroline are new to the US market and have not been studied in lock solutions.

Non-antibiotic antiseptics, such as ethanol and taurolidine, have also been used in a lock solution. Further, ion chelators (eg, citrate, EDTA) without antibiotics in solution are used in some institutions as the standard lock solution as an alternative to heparin- or saline-based solutions. ${ }^{49,50}$ Ethanol combinations with antibacterials have been highlighted in this review, and further details of ethanol as a potential lock solution are available elsewhere. ${ }^{14,31}$ Antifungal agents lack extensive stability and compatibility data, and their use is limited to select clinical cases. Available data are discussed elsewhere. ${ }^{31,51}$

\section{Logistical challenges and common questions}

While ALT represents a valuable option for many patients, relative unfamiliarity with this treatment modality may result in a delay or lack of ALT utilization. In order to optimize clinical outcomes with ALT, clinicians should consider the most common logistical challenges and questions for their practice setting in advance. The development of standardized protocols and/or institution-specific pathways may significantly improve utilization and success with ALT.

\section{Preparation}

The first step in considering ALT often requires locating preparation information for the desired antibiotic lock formulation. The development of local evidence-based recipes for pharmacy use along with corresponding order forms for prescriber use should significantly curb confusion surrounding ALT. Standardizing antibiotic concentrations, additives, and product expirations used in local practice should also increase familiarity and minimize the risk of medication errors with ALT. The information summarized herein can serve as a useful tool in developing such materials.

A particularly important additive to consider is the anticoagulant. Any acute changes regarding the addition of an anticoagulant, the specific agent used, and/or the concentration desired at the point of prescribing may render the current stability/compatibility information, and thus the preparation procedure, invalid. Such changes may significantly delay ALT initiation. Therefore, clinicians developing local ALT protocols should consider published evidence, availability of the anticoagulant, and local patient populations (eg, hemodialysis or oncology vs general medicine patients) before selecting a standard antibiotic lock formulation. Oftentimes, providing two or three standard lock formulations for each antibiotic agent may best suit local practice needs, such as one with antibiotic alone and one coformulated with highconcentration heparin $(5,000$ units $/ \mathrm{mL})$ for hemodialysis patients.

While heparin is historically the most common anticoagulant used in catheter locks, there is a growing body of data supporting the use of alternative anticoagulants such as the ion chelators, citrate or EDTA. A recent meta-analysis of 13 randomized controlled trials suggested citrate locks, specifically those coformulated with antibiotics, were superior to heparin locks in preventing CRBSI in patients with hemodialysis catheters (risk ratio [RR]: $0.39, P<0.001) .{ }^{33}$ Citrate locks were also associated with significantly lower risk of bleeding events compared to heparin locks in this patient population (RR: $0.48, P=0.002$ ), yet outcomes regarding catheter patency were comparable. ${ }^{33}$ In a 2010 position statement on the management of hemodialysis-CRBSI, the European Renal Best Practice (ERBP) supported ALT to prevent CRBSI and specifically recommended citrate $4 \%$ as the preferred agent/concentration. ${ }^{52}$ The beneficial effects of citrate are likely secondary to its calcium-chelating properties, which confer both antimicrobial and anticoagulant effects. ${ }^{53}$ The decreased risk of bleeding events is likely secondary to the rapid metabolism of citrate in the bloodstream. ${ }^{33}$ This latter property is advantageous in the event of the citrate-containing lock being inadvertently flushed into the systemic circulation. There are slightly fewer clinical data regarding the use of EDTA in catheter locks (mainly as preventive ALT in combination with minocycline), ${ }^{41-44}$ but the results are promising. A clinical study of a minocycline-EDTA lock as adjunctive treatment of CRBSI is currently ongoing. ${ }^{54}$ 
The debate over how and when to use anticoagulants in ALT is still evolving; yet, product availability of the alternative agents remains a potential logistical challenge. Availability of EDTA varies significantly by country. The current available formulation in the US is the salt, calcium EDTA $200 \mathrm{mg} / \mathrm{mL}$ (also known as calcium disodium versenate). ${ }^{55}$ Its only US Food and Drug Administration (FDA)-approved indication is the treatment of lead poisoning, meaning use in catheter locks is off-label. An alternative formulation of EDTA, edetate disodium, was removed from the US market in 2008 secondary to fatal errors in adults and children where the two EDTA formulations were confused and the incorrect agent was administered. ${ }^{56}$ Thus, current use of EDTA as an anticoagulant in ALT may be most appropriate as part of a formal research protocol.

Citrate formulations have also faced safety concerns and suffered from periodic market withdrawals. In 2000, the FDA recommended against use of high concentration citrate (46.7\%) as a catheter anticoagulant due to a case of a patient who experienced cardiac arrest, likely secondary to hypocalcemia, following a full-strength injection into a newly placed hemodialysis catheter. ${ }^{57}$ This formulation was voluntarily recalled in the US at the time and is now solely indicated as an anticoagulant for granulocytapheresis procedures ${ }^{57}$ It requires dilution prior to use and direct IV infusion is contraindicated. Additional serious adverse effects associated with high concentrations of citrate lock solutions continue to be reported worldwide.$^{58-60}$ The FDA currently recommends a lower citrate concentration of $4 \%$ for use in catheter locks. ${ }^{61}$ The ERBP also recommend a citrate $4 \%$ solution given its preferable benefit/ risk ratio compared to higher concentrations. ${ }^{52}$ Citrate $4 \%$ formulations are available in the US and worldwide, yet many are indicated solely for use in apheresis procedures (like the high-concentration citrate product). In the European Union, formulations of citrate $4 \%$ are available with the specific indication for use in CVC, such as a solution of citrate $4 \%$ alone (Citra-Lock ${ }^{\mathrm{TM}}$; Dirinco AG, Bern, Switzerland) and one of taurolidine-citrate $4 \%$ in combination (Taurolock ${ }^{\mathrm{TM}}$; Tauro-Implant GmbH, Winsen, Germany) ${ }^{61,62}$ Lastly, another potential limitation of calcium chelators is the inability to combine them with daptomycin locks until bioactivity of the daptomycin has been confirmed. ${ }^{31,45}$

Another issue regarding antibiotic lock preparation involves the relative waste of stock antibiotic solutions when only a small amount of an IV product is used to formulate the lock (eg, a daptomycin $500 \mathrm{mg}$ vial used for a $5 \mathrm{mg}$ lock). Standardization of expiration dates may allow for batch preparation of IV antibiotics with antibiotic locks, thereby minimizing product waste. Compliance with USP 797 guidelines for stability and compatibility of antibiotic locks remains somewhat challenging as the majority of current data is based on visual confirmation of physical stability as opposed to higher quality methodology such as high-performance liquid chromatography. However, there are some data suggesting certain antibiotic lock formulations have extended stability, eg, gentamicin $2.5 \mathrm{mg} / \mathrm{mL}$ and trisodium citrate $40 \mathrm{mg} / \mathrm{mL}$, which are stable at room temperature for 112 days. ${ }^{63}$ Such a formulation could be prepared in bulk and/or with IV doses of gentamicin. High cost antibiotics (eg, linezolid, daptomycin) are typically reserved for specific patient scenarios when these agents are selected as the optimal concomitant systemic therapy.

\section{Initiation and duration of therapy}

When a CRSBI is suspected, discussion on catheter removal versus salvage is likely to occur as part of an interdisciplinary management decision with the patient and team. If catheter salvage is being considered, even remotely, ALT should also be considered. For treatment of CRBSI, ALT initiation within the first 48-72 hours is associated with enhanced outcomes, ${ }^{20,64}$ preventing infection-related sequelae and improving the likelihood of catheter salvage. Delays of ALT are often common in practice as the decision to attempt CVC salvage may not be immediately known and other logistical issues discussed herein may prevent a standard protocol from being applicable for every specific case scenario. Nevertheless, active ALT protocols should help prevent treatment delay in a majority of patients.

Duration of ALT is often consistent with that of concurrent systemic therapy. Current guideline recommendations of targeting 10-14 days of ALT are based on limited comparative clinical data. ${ }^{5}$ Others have proposed abbreviated courses of therapy of 72 hours. ${ }^{65,66}$ Often the intended duration of therapy may be interrupted or shortened due to transitions of care, especially upon hospital discharge. Early discussions with case management and other personnel are needed to ensure continuation of ALT beyond an inpatient stay, if necessary. Although more data are needed to identify the optimal duration of ALT, abbreviated courses may offer a more convenient, cost-effective option and reduce the risk of resistance.

\section{Dwell time and catheter accessibility}

The optimal dwell time for ALT is unclear; however, the majority of clinical studies have proposed a minimum of 8 hours per day, with targets of $\geq 12$ hours per day to achieve optimal sterilization. ${ }^{67,68}$ Several in vitro models have shown 
exposure times of approximately 4 hours being effective in reducing bacterial colony counts, but the impact of shortened exposure times is unavailable for many antibiotic-pathogen combinations. ${ }^{45,69}$ Ideally, the solution may be locked in situ whenever the CVC is not in use. Catheter access often limits the dwell time, especially when the CVC is being used for IV antibiotics and other systemic therapies. The nurse or person responsible for medication administration should be actively engaged to ensure replacement of the lock solution if interruption of the dwell is required.

As alluded to above, the CVC is often being used for additional systemic therapies because it is often the only point of central venous access. Active discussions among the interdisciplinary team, including the patient's nurse, are required to ensure proper profiling and scheduling of the lock solution. Prior to profiling of the ALT, certain factors should be considered: 1) the number of lumens for the specific CVC and 2) IV therapies scheduled for administration through the CVC (especially any continuous IV infusions). In cases of a multi-lumen CVC, the optimal scenario is to lock all lumens with the antibiotic solution. If a continuous IV fluid is being administered in a patient with multiple lumens, the nurse may be instructed to rotate lumens every 12-24 hours, alternating the lock solution to allow for exposure of each lumen to the ALT. This may present a significant challenge, and proper labeling of CVC lumens can be used to identify a rotation schedule. However, if a significant number of scheduled IV therapies are expected, an attempt should be made to coadminister them wherever possible (based on known compatibility data). Alternatively, holding continuous infusions like fluids or TPN for brief (24-36 hour) periods initially $^{70}$ or changing the administration to a peripheral IV access may be viable options in select patients.

\section{Risks of antibiotic lock therapy}

There are a number of potential and documented risks associated with ALT. As with any solution allowed to dwell in a catheter lumen, the potential for occlusion exists. This risk is expected to be decreased if the solution also contains an anticoagulant. Flushing of the lock solution may expose the patient to unnecessary systemic concentrations of antibiotics and/or anticoagulants - a risk that increases with flushing frequency. Although some systemic exposure from CVC leakage may be expected, the risk of toxicity is likely quite limited if the lock is aspirated as directed. However, highconcentration antibiotic solutions associated with serious toxicities, eg, aminoglycosides and ototoxicity, should still be avoided. ${ }^{18}$ The greatest risk of flushing is likely in lock solutions containing higher concentrations of anticoagulants, particularly heparin $>1,000$ units $/ \mathrm{mL}$ or citrate $30 \%-46.7 \%$. At these concentrations, the patient may be exposed to systemically active doses that would increase risk of bleeding or hypocalcemia and arrhythmias, respectively. ${ }^{57,71}$ Low-level exposure of antibiotics may potentially increase the risk of resistance. ${ }^{72,73}$ However, this concern should be weighed against findings that routine prophylactic use of ALT may reduce the general rate of CRBSI, thereby decreasing overall need for systemic antibiotic therapy. ${ }^{15,33}$

\section{Conclusion}

Given the integral role of long-term CVC use in health care delivery, ALT remains an important option for the preventive and adjunctive treatment of CRBSI. A wide variety of antibiotics have been evaluated for clinical use, with the largest body of data available for vancomycin and gentamicin. In order to ensure optimal clinical outcomes with ALT, clinicians should consider common technical questions and logistical challenges in advance. These include lock preparation procedures, use of additives (eg, heparin, citrate, or EDTA), timing of initiation and therapy duration, dwell time and catheter accessibility, and risks associated with ALT. Development of local protocols is recommended in order to assist clinicians with these potential issues and facilitate utilization of ALT where appropriate.

\section{Disclosure}

$\mathrm{JJ}$ and $\mathrm{PBB}$ receive research support from Cubist Pharmaceuticals. PBB receives research support and consultation fees from Durata Therapeutics.

\section{References}

1. Centers for Disease Control and Prevention (CDC). Vital Signs. Making Health Care Safer: Reducing Bloodstream Infections. Atlanta, GA: Centers for Disease Control and Prevention; 2011. Available from: http://www. cdc.gov/VitalSigns/pdf/2011-03-vitalsigns.pdf. Accessed May 10, 2014.

2. Dudeck MA, Weiner LM, Allen-Bridson K, et al. National Healthcare Safety Network (NHSN) report, data summary for 2012, Deviceassociated module. Am J Infect Control. 2013;41(12):1148-1166.

3. Centers for Disease Control and Prevention (CDC). Vital Signs: Central line-associated bloodstream infections - United States, 2001, 2008, and 2009. MMWR Morb Mortal Wkly Rep. 2011;60(8):243-248.

4. Centers for Disease Control and Prevention (CDC). Guidelines for the Prevention of Intravascular Catheter-Related Infections, 2011. Atlanta, GA: Centers for Disease Control and Prevention; 2011. Available from: http://www.cdc.gov/hicpac/pdf/guidelines/bsi-guidelines-2011.pdf. Accessed May 10, 2014.

5. Mermel LA, Allon M, Bouza E, et al. Clinical practice guidelines for the diagnosis and management of intravascular catheter-related infection: 2009 Update by the Infectious Diseases Society of America. Clin Infect Dis. 2009;49(1):1-45.

6. Bustos C, Aguinaga A, Carmona-Torre F, Del Pozo JL. Long-term catheterization: current approaches in the diagnosis and treatment of port-related infections. Infect Drug Resist. 2014;7:25-35. 
7. Costerton JW, Lewandowski Z, DeBeer D, Caldwell D, Korber D, James G. Biofilms, the customized microniche. J Bacteriol. 1994;176(8): 2137-2142.

8. Nichols WW, Dorrington SM, Slack MP, Walmsley HL. Inhibition of tobramycin diffusion by binding to alginate. Antimicrob Agents Chemother. 1988;32(4):518-523.

9. Jefferson KK, Goldmann DA, Pier GB. Use of confocal microscopy to analyze the rate of vancomycin penetration through Staphylococcus aureus biofilms. Antimicrob Agents Chemother. 2005;49(6): 2467-2473.

10. Araújo PA, Mergulhão F, Melo L, Simões M. The ability of an antimicrobial agent to penetrate a biofilm is not correlated with its killing or removal efficiency. Biofouling. Epub 2014 Apr 29.

11. Anderl JN, Franklin MJ, Stewart PS. Role of antibiotic penetration limitation in Klebsiella pneumoniae biofilm resistance to ampicillin and ciprofloxacin. Antimicrob Agents Chemother. 2000;44(7):1818-1824.

12. Banin E, Brady KM, Greenberg EP. Chelator-induced dispersal and killing of Pseudomonas aeruginosa cells in a biofilm. Appl Environ Microbiol. 2006;72(3):2064-2069.

13. Raad II, Fang X, Keutgen XM, Jiang Y, Sherertz R, Hachem R. The role of chelators in preventing biofilm formation and catheter-related bloodstream infections. Curr Opin Infect Dis. 2008;21(4):385-392.

14. Maiefski M, Rupp ME, Hermsen ED. Ethanol lock technique: review of the literature. Infect Control Hosp Epidemiol. 2009;30(11):1096-1108.

15. Jaffer Y, Selby NM, Taal MW, Fluck RJ, McIntyre CW. A meta-analysis of hemodialysis catheter locking solutions in the prevention of catheterrelated infection. Am J Kidney Dis. 2008;51(2):233-241.

16. O'Horo JC, Silva GL, Safdar N. Anti-infective locks for treatment of central line-associated bloodstream infection: a systematic review and meta-analysis. Am J Nephrol. 2011;34(5):415-422.

17. Polgreen PM, Beekmann SE, Diekema DJ, Sherertz RJ. Wide variability in the use of antimicrobial lock therapy and prophylaxis among infectious diseases consultants. Infect Control Hosp Epidemiol. 2010;31(5): $554-557$.

18. Saxena AK, Panhotra BR, Naguib M. Sudden irreversible sensoryneural hearing loss in a patient with diabetes receiving amikacin as an antibiotic-heparin lock. Pharmacotherapy. 2002;22(1):105-108.

19. Rao JS, O'Meara A, Harvey T, Breatnach F. A new approach to the management of Broviac catheter infection. J Hosp Infect. 1992;22(2): 109-116.

20. Onder AM, Chandar J, Billings AA, et al. Comparison of early versus late use of antibiotic locks in the treatment of catheter-related bacteremia. Clin J Am Soc Nephrol. 2008;3(4):1048-1056.

21. Poole CV, Carlton D, Bimbo L, Allon M. Treatment of catheter-related bacteraemia with an antibiotic lock protocol: effect of bacterial pathogen. Nephrol Dial Transplant. 2004;19(5):1237-1244.

22. Haimi-Cohen Y, Husain N, Meenan J, Karayalcin G, Lehrer M, Rubin LG. Vancomycin and ceftazidime bioactivities persist for at least 2 weeks in the lumen in ports: simplifying treatment of portassociated bloodstream infections by using the antibiotic lock technique. Antimicrob Agents Chemother. 2001;45(5):1565-1567.

23. Anthony TU, Rubin LG. Stability of antibiotics used for antibiotic-lock treatment of infections of implantable venous devices (ports). Antimicrob Agents Chemother. 1999;43(8):2074-2076.

24. Robinson JL, Tawfik G, Saxinger L, Stang L, Etches W, Lee B. Stability of heparin and physical compatibility of heparin/antibiotic solutions in concentrations appropriate for antibiotic lock therapy. J Antimicrob Chemother. 2005;56(5):951-953.

25. Boorgu R, Dubrow AJ, Levin NW, et al. Adjunctive antibiotic/ anticoagulant lock therapy in the treatment of bacteremia associated with the use of a subcutaneously implanted hemodialysis access device. ASAIO J. 2000;46(6):767-770.

26. Santarpia L, Pasanisi F, Alfonsi L, et al. Prevention and treatment of implanted central venous catheter $(\mathrm{CVC})$ - related sepsis: a report after six years of home parenteral nutrition (HPN). Clin Nutr. 2002;21(3):207-211.
27. Del Pozo JL, Alonso M, Serrera A, Hernaez S, Aguinaga A, Leiva J. Effectiveness of the antibiotic lock therapy for the treatment of port-related enterococci, Gram-negative, or Gram-positive bacilli bloodstream infections. Diagn Microbiol Infect Dis. 2009;63(2): 208-212.

28. Lee MY, Ko KS, Song JH, Peck KR. In vitro effectiveness of the antibiotic lock technique (ALT) for the treatment of catheter-related infections by Pseudomonas aeruginosa and Klebsiella pneumoniae. J Antimicrob Chemother. 2007;60(4):782-787.

29. Lee HR, Lee YK, Song YL, et al. [Treatment of catheter-related bacteremia with an antibiotic lock protocol in hemodialysis patients]. Korean J Nephrol. 2005;24(6):903-911. Korean.

30. Saxinger L, Williams K, Lyon M, Mochurok M. Stability of antibiotics in heparin at $37^{\circ} \mathrm{C}$ : towards antibiotic locks for central venous catheter related infections. In: Programme and Abstracts of the 39th Interscience Conference on Antimicrobial Agents and Chemotherapy; September 26-29, 1999; San Francisco, CA.

31. Bookstaver PB, Rokas KE, Norris LB, Edwards JM, Sherertz RJ. Stability and compatibility of antimicrobial lock solutions. Am J Health Syst Pharm. 2013;70(24):2185-2198.

32. Bastani B. The myth of incompatibility of gentamicin and heparin revisited. J Nephrol. 2011;24(2):192-195.

33. Zhao Y, Li Z, Zhang L, et al. Citrate versus heparin lock for hemodialysis catheters: a systematic review and meta-analysis of randomized controlled trials. Am J Kidney Dis. 2014;63(3):479-490.

34. Dotson B, Lynn S, Savakis K, Churchwell MD. Physical compatibility of $4 \%$ sodium citrate with selected antimicrobial agents. Am J Health Syst Pharm. 2010;67(14):1195-1198.

35. Onder AM, Chandar J, Simon N, et al. Comparison of tissue plasminogen activator-antibiotic locks with heparin-antibiotic locks in children with catheter-related bacteraemia. Nephrol Dial Transplant. 2008;23(8): 2604-2610.

36. Onder AM, Chandar J, Billings A, et al. Prophylaxis of catheter-related bacteremia using tissue plasminogen activator-tobramycin locks. Pediatr Nephrol. 2009;24(11):2233-2243.

37. Sofroniadou S, Revela I, Smirloglou D, et al. Linezolid versus vancomycin antibiotic lock solution for the prevention of nontunneled catheter-related blood stream infections in hemodialysis patients: a prospective randomized study. Semin Dial. 2012;25(3):344-350.

38. Droste JC, Jeraj HA, MacDonald A, Farrington K. Stability and in vitro efficacy of antibiotic-heparin lock solutions potentially useful for treatment of central venous catheter-related sepsis. J Antimicrob Chemother. 2003;51(4):849-855.

39. LaPlante KL, Woodmansee S, Mermel LA. Compatibility and stability of telavancin and vancomycin in heparin or sodium citrate lock solutions. Am J Health Syst Pharm. 2012;69(16):1405-1409.

40. Messing B, Peitra-Cohen S, Debure A, Beliah M, Bernier JJ. Antibioticlock technique: a new approach to optimal therapy for catheter-related sepsis in home-parenteral nutrition patients. JPEN J Parenter Enteral Nutr. 1988;12(2):185-189.

41. Chatzinikolaou I, Zipf TF, Hanna H, et al. Minocycline-ethylenediaminetetraacetate lock solution for the prevention of implantable port infections in children with cancer. Clin Infect Dis. 2003;36(1): 116-119.

42. Feely T, Copley A, Bleyer AJ. Catheter lock solutions to prevent bloodstream infections in high-risk hemodialysis patients. Am J Nephrol. 2007;27(1):24-29.

43. Campos RP, do Nascimento MM, Chula DC, Riella MC. Minocycline-EDTA lock solution prevents catheter-related bacteremia in hemodialysis. J Am Soc Nephrol. 2011;22(10):1939-1945.

44. Nori US, Manoharan A, Yee J, Besarab A. Comparison of low-dose gentamicin with minocycline as catheter lock solutions in the prevention of catheter-related bacteremia. Am J Kidney Dis. 2006;48(4):596-605.

45. Bookstaver PB, Williamson JC, Tucker BK, Raad II, Sherertz RJ. Activity of novel antibiotic lock solutions in a model against isolates of catheterrelated bloodstream infections. Ann Pharmacother. 2009;43(2):210-219. 
46. Vincentelli J, Braguer D, Guillet P, et al. Formulation of a flush solution of heparin, vancomycin, and colistin for implantable access systems in oncology. J Oncol Pharm Pract. 1997;3(1):18-23.

47. Ozbek B, Mataraci E. In vitro effectiveness of colistin, tigecycline and levofloxacin alone and combined with clarithromycin and/or heparin as lock solutions against embedded Acinetobacter baumannii strains. J Antimicrob Chemother. 2013;68(4):827-830.

48. Bookstaver P, Premnath P, Edwards J. Evaluation of compatibility and stability of daptomycin in an antibiotic-anticoagulant lock solution. In: American College of Clinical Pharmacy Annual Meeting; October 21-24, 2012; Hollywood, FL.

49. Maki DG, Ash SR, Winger RK, Lavin P; AZEPTIC Trial Investigators. A novel antimicrobial and antithrombotic lock solution for hemodialysis catheters: a multi-center, controlled, randomized trial. Crit Care Med 2011;39(4):613-620.

50. Raad I, Bodey GP. Novel antimicrobial catheter lock solution: a new direction in which chelators replace heparin. Crit Care Med. 2011;39(4): 875-876.

51. DiMondi PV, Townsend ML, Johnson M, Durkin M. Antifungal catheter lock therapy for the management of a persistent Candida albicans bloodstream infection in an adult receiving hemodialysis. Pharmacotherapy. 2014;34(7):e120-e127.

52. Vanholder R, Canaud B, Fluck R, et al. Diagnosis, prevention and treatment of haemodialysis catheter-related bloodstream infections (CRBSI): a position statement of European Renal Best Practice (ERBP). NDT Plus. 2010;3(3):234-246.

53. Pierce DA, Rocco MV. Trisodium citrate: an alternative to unfractionated heparin for hemodialysis catheter dwells. Pharmacotherapy. 2010;30(11):1150-1158.

54. MD Anderson Cancer Center; Triax. Antimicrobial catheter lock solution for the treatment of central line associated bloodstream infection (CLABSI). Available from: http://clinicaltrials.gov/ct2/show/ NCT01539343. NLM identifier: NCT01539343. Accessed June 20, 2014.

55. LexiComp. Edetate Calcium Disodium, Calcium EDTA [Drug Monograph]; 2009. Available from: http://online.lexi.com/lco/action/doc/ retrieve/docid/250/413457\#synlist. Accessed June 20, 2014.

56. US Food and Drug Administration. Public health advisory: edetate disodium (marketed as Endrate and generic products); 2008. Available from: http://www.fda.gov/Drugs/DrugSafety/PostmarketDrugSafety InformationforPatientsandProviders/ucm051138.htm. Accessed June 20,2014

57. US Food and Drug Administration. Warning on Tricitrasol Dialysis Catheter Anticoagulant. FDA Talk Paper. Rockville, MD: Public Health Service; 2000;16:4-14-2000.

58. Punt CD, Boer WE. Cardiac arrest following injection of concentrated trisodium citrate. Clin Nephrol. 2008;69(4):317-318.

59. Willicombe MK, Vernon K, Davenport A. Embolic complications from central venous hemodialysis catheters used with hypertonic citrate locking solution. Am J Kidney Dis. 2010;55(2):348-351.

60. Schilcher G, Scharnagl H, Horina JH, et al. Trisodium citrate induced protein precipitation in haemodialysis catheters might cause pulmonary embolism. Nephrol Dial Transplant. 2012;27(7): 2953-2957.

61. Tauro-Implant GmbH [webpage on the Internet]. FAQ. TauroLock Antimicrob Catheter Lock Syst Provide Patency Infect Control; 2010. Available from: http://www.taurolock.com/en/faq. Accessed June 20, 2014.

62. Dirinco [webpage on the Internet]. FAQs. Citra-Lock Catheter Lock Solut; 2013. Available from: http://www.citra-lock.com/index.php/en/ science-behind/faqs.html\#4-what-are-the-side-effects-of-citra-lock. Accessed June 20, 2014.

63. Cote D, Lok CE, Battistella M, Vercaigne L. Stability of trisodium citrate and gentamicin solution for catheter locks after storage in plastic syringes at room temperature. Can J Hosp Pharm. 2010;63(4): 304-311.
64. Bookstaver PB, Gerrald KR, Moran RR. Clinical outcomes of antimicrobial lock solutions used in a treatment modality: a retrospective case series analysis. Clin Pharmacol Adv Appl. 2010;2:123-130.

65. Tendas A, Niscola P, Cupelli L, et al. Controversies on antibiotic lock technique duration: experience with a 3-day course for hematological patients. Infect Control Hosp Epidemiol. 2011;32(4): 408-410.

66. Sánchez-Muñoz A, Aguado JM, López-Martín A, et al. Usefulness of antibiotic-lock technique in management of oncology patients with uncomplicated bacteremia related to tunneled catheters. Eur J Clin Microbiol Infect Dis. 2005;24(4):291-293.

67. Segarra-Newnham M, Martin-Cooper EM. Antibiotic lock technique: a review of the literature. Ann Pharmacother. 2005;39(2):311-318.

68. Fernandez-Hidalgo N, Almirante B, Calleja R, et al. Antibiotic-lock therapy for long-term intravascular catheter-related bacteraemia: results of an open, non-comparative study. J Antimicrob Chemother. 2006;57(6):1172-1180.

69. Raad I, Hanna H, Dvorak T, Chaiban G, Hachem R. Optimal antimicrobial catheter lock solution, using different combinations of minocycline, EDTA, and 25-percent ethanol, rapidly eradicates organisms embedded in biofilm. Antimicrob Agents Chemother. 2007;51(1):78-83.

70. Messing B, Man F, Colimon R, Thuillier F, Beliah M. Antibiotic-lock technique is an effective treatment of bacterial catheter-related sepsis during parenteral nutrition. Clin Nutr. 1990;9(4):220-225.

71. Yevzlin AS, Sanchez RJ, Hiatt JG, et al. Concentrated heparin lock is associated with major bleeding complications after tunneled hemodialysis catheter placement. Semin Dial. 2007;20(4):351-354.

72. Abbas SA, Haloob IA, Taylor SL, et al. Effect of antimicrobial locks for tunneled hemodialysis catheters on bloodstream infection and bacterial resistance: a quality improvement report. Am J Kidney Dis. 2009;53(3): 492-502.

73. Landry DL, Braden GL, Gobeille SL, Haessler SD, Vaidya CK, Sweet SJ. Emergence of gentamicin-resistant bacteremia in hemodialysis patients receiving gentamicin lock catheter prophylaxis. Clin J Am Soc Nephrol. 2010;5(10):1799-1804.

74. Walters MC 3rd, Roe F, Bugnicourt A, Franklin MJ, Stewart PS. Contributions of antibiotic penetration, oxygen limitation, and low metabolic activity to tolerance of Pseudomonas aeruginosa biofilms to ciprofloxacin and tobramycin. Antimicrob Agents Chemother. 2003;47(1):317-323.

75. Shigeta M, Tanaka G, Komatsuzawa H, Sugai M, Suginaka H, Usui T. Permeation of antimicrobial agents through Pseudomonas aeruginosa biofilms: a simple method. Chemotherapy. 1997;43(5):340-345.

76. Singh R, Ray P, Das A, Sharma M. Penetration of antibiotics through Staphylococcus aureus and Staphylococcus epidermidis biofilms. J Antimicrob Chemother. 2010;65(9):1955-1958.

77. Dunne WM Jr, Mason EO Jr, Kaplan SL. Diffusion of rifampin and vancomycin through a Staphylococcus epidermidis biofilm. Antimicrob Agents Chemother. 1993;37(12):2522-2526.

78. Zheng Z, Stewart PS. Penetration of rifampin through Staphylococcus epidermidis biofilms. Antimicrob Agents Chemother. 2002;46(3): 900-903.

79. Rodríguez-Martínez JM, Ballesta S, García I, Conejo MC, Pascual A. Actividad y permeabilidad de linezolid y vancomicina en biocapas de Staphylococcus epidermidis [Activity and penetration of linezolid and vancomycin against Staphylococcus epidermidis biofilms]. Enferm Infecc Microbiol Clin. 2007;25(7):425-428. Spanish.

80. Stewart PS, Davison WM, Steenbergen JN. Daptomycin rapidly penetrates a Staphylococcus epidermidis biofilm. Antimicrob Agents Chemother. 2009;53(8):3505-3507.

81. Lin M, He L, Gao J, et al. Penetration of erythromycin through Staphylococcus epidermidis biofilm. Chin Med J (Engl). 2013;126(14): 2647-2651.

82. Hoyle BD, Alcantara J, Costerton JW. Pseudomonas aeruginosa biofilm as a diffusion barrier to piperacillin. Antimicrob Agents Chemother. 1992;36(9):2054-2056. 
83. Darouiche RO, Dhir A, Miller AJ, Landon GC, Raad II, Musher DM. Vancomycin penetration into biofilm covering infected prostheses and effect on bacteria. J Infect Dis. 1994;170(3):720-723.

84. Robinson JL, Tawfik G, Roth A. Barriers to antibiotic lock therapy in children with intravascular catheter-related bloodstream infections. Pediatr Infect Dis J. 2005;24(10):944.

85. Elwood RL, Spencer SE. Successful clearance of catheter-related bloodstream infection by antibiotic lock therapy using ampicillin. Ann Pharmacother. 2006;40(2):347-350.

86. Krzywda EA, Andris DA, Edmiston CE, Quebbeman EJ. Treatment of Hickman catheter sepsis using antibiotic lock technique. Infect Control Hosp Epidemiol. 1995;16(10):596-598.

87. Davanipur M, Pakfetrat M, Roozbeh J. Cloxacillin as an antibiotic lock solution for prevention of catheter-associated infection. Iran J Kidney Dis. 2011;5(5):328-331.

88. Johnson DC, Johnson FL, Goldman S. Preliminary results treating persistent central venous catheter infections with the antibiotic lock technique in pediatric patients. Pediatr Infect Dis J. 1994;13(10): 930-931.

89. Silva TNV, Mendes ML, Abrão JMG, Caramori JT, Ponce D. Successful prevention of tunneled central catheter infection by antibiotic lock therapy using cefazolin and gentamicin. Int Urol Nephrol. 2013;45(5):1405-1413.

90. Chauhan A, Lebeaux D, Decante B, et al. A rat model of central venous catheter to study establishment of long-term bacterial biofilm and related acute and chronic infections. PLoS One. 2012;7(5):e37281.

91. Maya ID, Carlton D, Estrada E, Allon M. Treatment of dialysis catheterrelated Staphylococcus aureus bacteremia with an antibiotic lock: a quality improvement report. Am J Kidney Dis. 2007;50(2):289-295.

92. Chiou PF, Chang CC, Wen YK, Yang Y. Antibiotic lock technique reduces the incidence of temporary catheter-related infections. Clin Nephrol. 2006;65(6):419-422.

93. Kim SH, Song KI, Chang JW, et al. Prevention of uncuffed hemodialysis catheter-related bacteremia using an antibiotic lock technique: a prospective, randomized clinical trial. Kidney Int. 2006;69(1): $161-164$

94. Vercaigne LM, Zelenitsky SA, Findlay I, Bernstein K, Penner SB. An in vitro evaluation of the antibiotic/heparin lock to sterilize central venous haemodialysis catheters. JAntimicrob Chemother. 2002;49(4): 693-696.

95. Vercaigne LM, Sitar DS, Penner SB, Bernstein K, Wang GQ, Burczynski FJ. Antibiotic-heparin lock: in vitro antibiotic stability combined with heparin in a central venous catheter. Pharmacotherapy. 2000;20(4):394-399.

96. Krishnasami Z, Carlton D, Bimbo L, et al. Management of hemodialysis catheter-related bacteremia with an adjunctive antibiotic lock solution. Kidney Int. 2002;61(3):1136-1142.

97. Shah J, Feinfeld DA. Use of 'locked-in' antibiotic to treat an unusual gram-negative hemodialysis catheter infection. Nephron. 2000;85(4): 348-350.

98. Lee YK, Kim JK, Oh SE, Lee J, Noh JW. Successful antibiotic lock therapy in patients with refractory peritonitis. Clin Nephrol. 2009;72(6):488-491.

99. Saxena AK, Panhotra BR. The impact of catheter-restricted filling with cefotaxime and heparin on the lifespan of temporary hemodialysis catheters: a case controlled study. J Nephrol. 2005;18(6):755-763.

100. Saxena AK, Panhotra BR, Sundaram DS, Morsy MN, Al-Ghamdi AM. Enhancing the survival of tunneled haemodialysis catheters using an antibiotic lock in the elderly: a randomised, double-blind clinical trial. Nephrology (Carlton). 2006;11(4):299-305.

101. Saxena AK, Panhotra BR, Sundaram DS, et al. Tunneled catheters' outcome optimization among diabetics on dialysis through antibioticlock placement. Kidney Int. 2006;70(9):1629-1635.

102. Saxena AK, Panhotra BR, Al-hafiz AA, Sundaram DS, Abu-Oyun B, Al Mulhim K. Cefotaxime-heparin lock prophylaxis against hemodialysis catheter-related sepsis among Staphylococcus aureus nasal carriers. Saudi J Kidney Dis Transpl. 2012;23(4):743-754.
103. Mortazavi M, Alsaeidi S, Sobhani R, et al. Successful prevention of tunneled, central catheter infection by antibiotic lock therapy using cefotaxime. J Res Med Sci. 2011;16(3):303-309.

104. Baker DS, Waldrop B, Arnold J. Compatibility and stability of cefotaxime, vancomycin, and ciprofloxacin in antibiotic lock solutions containing heparin. Int J Pharm Compd. 2010;14(4):346-349.

105. Capdevila JA, Segarra A, Planes AM, et al. Successful treatment of haemodialysis catheter-related sepsis without catheter removal. Nephrol Dial Transplant. 1993;8(3):231-234.

106. Capdevila JA, Gavaldà J, Fortea J, et al. Lack of antimicrobial activity of sodium heparin for treating experimental catheter-related infection due to Staphylococcus aureus using the antibiotic-lock technique. Clin Microbiol Infect. 2001;7(4):206-212.

107. Messing B. Catheter-sepsis during home parenteral nutrition: use of the antibiotic-lock technique. Nutrition. 1998;14(5):466-468.

108. Domingo P, Fontanet A, Sánchez F, Allende L, Vazquez G. Morbidity associated with long-term use of totally implantable ports in patients with AIDS. Clin Infect Dis. 1999;29(2):346-351.

109. Cesaro S, Cavaliere M, Spiller M, et al. A simplified method of antibiotic lock therapy for Broviac-Hickman catheters using a CLC 2000 connector device. Support Care Cancer. 2007;15(1):95-99.

110. Bastani B, Amin K, Herr A. Prolonged stability of stored vancomycin, gentamicin, and heparin for use in the antibiotic-lock technique. ASAIOJ. 2005;51(6):761-763.

111. Battistella M, Vercaigne LM, Cote D, Lok CE. Antibiotic lock: in vitro stability of gentamicin and sodium citrate stored in dialysis catheters at 37 degrees C. Hemodial Int. 2010;14(3):322-326.

112. Onder AM, Kato T, Simon N, et al. Prevention of catheter-related bacteremia in pediatric intestinal transplantation/short gut syndrome children with long-term central venous catheters. Pediatr Transplant. 2007;11(1):87-93.

113. Castagnola E, Moroni C, Gandullia P, et al. Catheter lock and systemic infusion of linezolid for treatment of persistent Broviac catheter-related staphylococcal bacteremia. Antimicrob Agents Chemother. 2006;50(3): 1120-1121.

114. Henrickson KJ, Powell KR, Schwartz CL. A dilute solution of vancomycin and heparin retains antibacterial and anticoagulant activities. J Infect Dis. 1988;157(3):600-601.

115. Yao JD, Arkin CF, Karchmer AW. Vancomycin stability in heparin and total parenteral nutrition solutions: novel approach to therapy of central venous catheter-related infections. JPEN J Parenter Enteral Nutr. 1992;16(3):268-274.

116. Soriano A, Bregada E, Marqués JM, et al. Decreasing gradient of antibiotic concentration in the lumen of catheters locked with vancomycin. Eur J Clin Microbiol Infect Dis. 2007;26(9):659-661.

117. Battistella M, Walker S, Law S, Lok C. Antibiotic lock: in vitro stability of vancomycin and four percent sodium citrate stored in dialysis catheters at 37 degrees C. Hemodial Int. 2009;13(3):322-328.

118. Safdar N, Maki DG. Use of vancomycin-containing lock or flush solutions for prevention of bloodstream infection associated with central venous access devices: a meta-analysis of prospective, randomized trials. Clin Infect Dis. 2006;43(4):474-484.

119. Dixon JJ, Steele M, Makanjuola AD. Anti-microbial locks increase the prevalence of Staphylococcus aureus and antibiotic-resistant Enterobacter: observational retrospective cohort study. Nephrol Dial Transplant. 2012;27(9):3575-3581.

120. Fortún J, Grill F, Martín-Dávila P, et al. Treatment of long-term intravascular catheter-related bacteraemia with antibiotic-lock therapy. J Antimicrob Chemother. 2006;58(4):816-821.

121. Beigi AA, Khansoltani S, Masoudpour H, Atapour AA, Eshaghian A, Khademi EF. Influence of intralumenal and antibiotic-lock of vancomycin on the rate of catheter removal in the patients with permanent hemodialysis catheters. Saudi J Kidney Dis Transplant. 2010;21(1): 54-58.

122. Del Pozo JL, Aguinaga A, Garcia-Fernandez N, et al. Intra-catheter leukocyte culture to monitor hemodialysis catheter colonization. A prospective study to prevent catheter-related bloodstream infections. Int J Artif Organs. 2008;31(9):820-826. 
123. Cuntz D, Michaud L, Guimber D, Husson MO, Gottrand F, Turck D. Local antibiotic lock for the treatment of infections related to central catheters in parenteral nutrition in children. JPEN J Parenter Enteral Nutr. 2002;26(2):104-108.

124. Van Praagh ADG, Li T, Zhang S, et al. Daptomycin antibiotic lock therapy in a rat model of staphylococcal central venous catheter biofilm infections. Antimicrob Agents Chemother. 2011;55(9): 4081-4089.

125. Ortega R, Salmerón-García A, Cabeza J, Capitán-Vallvey LF, Navas N. Stability of daptomycin $5 \mathrm{mg} / \mathrm{mL}$ and heparin sodium 100 units $/ \mathrm{mL}$ combined in lactated Ringer's injection and stored in polypropylene syringes at 4 and $-20^{\circ} \mathrm{C}$. Am J Health Syst Pharm. 2014;71(11): 956-959.

126. Del Pozo JL, Rodil R, Aguinaga A, et al. Daptomycin lock therapy for grampositive long-term catheter-related bloodstream infections. Int J Clin Pract. 2012;66(3):305-308.

127. Estes R, Theusch J, Beck A, Pitrak D, Mullane KM. Activity of daptomycin with or without 25 percent ethanol compared to combinations of minocycline, EDTA, and 25 percent ethanol against methicillinresistant Staphylococcus aureus isolates embedded in biofilm. Antimicrob Agents Chemother. 2013;57(4):1998-2000.
128. Al Akhrass F, Hachem R, Mohamed JA, et al. Central venous catheterassociated Nocardia bacteremia in cancer patients. Emerg Infect Dis. 2011;17(9):1651-1658.

129. Raad I, Hachem R, Tcholakian RK, Sherertz R. Efficacy of minocycline and EDTA lock solution in preventing catheter-related bacteremia, septic phlebitis, and endocarditis in rabbits. Antimicrob Agents Chemother. 2002;46(2):327-332.

130. Aslam S, Trautner BW, Ramanathan V, Darouiche RO. Pilot trial of $\mathrm{N}$-acetylcysteine and tigecycline as a catheter-lock solution for treatment of hemodialysis catheter-associated bacteremia. Infect Control Hosp Epidemiol. 2008;29(9):894-897.

131. Bartalesi F, Veloci S, Baragli F, et al. Successful tigecycline lock therapy in a Lactobacillus rhamnosus catheter-related bloodstream infection. Infection. 2012;40(3):331-334.

132. Ghannoum MA, Isham N, Jacobs MR. Antimicrobial activity of B-Lock against bacterial and Candida spp. causing catheter-related bloodstream infections. Antimicrob Agents Chemother. 2011;55(9): 4430-4431.
Infection and Drug Resistance

\section{Publish your work in this journal}

Infection and Drug Resistance is an international, peer-reviewed openaccess journal that focuses on the optimal treatment of infection (bacterial, fungal and viral) and the development and institution of preventive strategies to minimize the development and spread of resistance. The journal is specifically concerned with the epidemiology of antibiotic

\section{Dovepress}

resistance and the mechanisms of resistance development and diffusion in both hospitals and the community. The manuscript management system is completely online and includes a very quick and fair peerreview system, which is all easy to use. Visit http://www.dovepress.com/ testimonials.php to read real quotes from published authors. 